\title{
Rail Passenger Equipment Accidents and the Evaluation of Crashworthiness Strategies
}

\author{
David C. Tyrell \\ Volpe National Transportation Systems Center \\ U.S. Department of Transportation
}

\section{ABSTRACT}

The U.S. Department of Transportation's Federal Railroad Administration's (FRA) Office of Research and Development has been conducting research into rail equipment crashworthiness. The approach taken in conducting this research has been to review relevant accidents, identify options for design modifications to improve occupant survivability, and to apply analytic tools and testing techniques for evaluating the effectiveness of these strategies. Accidents have been grouped into three categories: train-to-train collisions, collisions with objects, such as grade crossing collisions, and derailments and other single train events. In order to determine the potential effectiveness of improved crashworthiness equipment, computer models have been used to simulate the behavior of conventional and modified equipment in scenarios based on accidents.

\section{INTRODUCTION}

Train accidents can be tragic events, with loss of life and serious injuries. The crashworthiness features of the train are intended to minimize fatalities and injuries if an accident does occur. The purpose of such features is to preserve sufficient space for the occupants to ride out the collision, and to maintain the forces and decelerations imparted to the occupants within survivable levels. Structural features of the cars, such as longitudinal strength of the carbody and crush zones at the ends of cars, influence how well the cars preserve the occupant volume during a collision and the decelerations imparted to the occupants. Occupant protection features inside the car, such as compartmentalization, influence the forces imparted to the occupants. 


\subsection{Research}

The FRA conducts research on rail equipment, track, and operation safety. Research areas include collision avoidance measures such as positive train control and strategies for minimizing operator fatigue, as well as equipment crashworthiness (1). Keeping the trains separated is the first line of defense in assuring passenger and operator safety, while equipment crashworthiness is the last line of defense. The information from this research has been used to develop federal safety regulations for passenger equipment, which address emergency preparedness, fire safety, software safety, brakes, vehicle dynamic performance, and equipment crashworthiness (2). (See a companion paper for a discussion of federal crashworthiness regulations (3).)

The overall objective of the rail equipment crashworthiness research is to develop design strategies with improved crashworthiness over existing designs. The approach used in conducting this research is illustrated in the flow diagram shown in Figure 1. Information from train accidents is used in all aspects of this research. The rail equipment crashworthiness research approach is as follows:

1. Define the collision scenarios of concern. For developing crashworthiness, the accidents identify the conditions that, if possible, are to be survived. These conditions include the collision or derailment speed, the train and other objects, and the track conditions. Some accidents happen under such circumstances - for instance at such great speed -- that it is a practical impossibility to survive such collisions. Very high-speed collisions require the use of buffer cars or other measures which have not been considered practical. The collision scenarios of concern are developed by reviewing the relevant accidents, by statistically analyzing the accident data, as well as by failure analysis of collision avoidance measures $(4,5)$. The goal in developing the collision scenarios of concern is to develop a limited number of scenarios that bound the range of likely collisions. These scenarios are used as the basis for evaluating the effectiveness of crashworthiness design options.

2a. Develop information on the features of existing designs which influence crashworthiness. Information on the design details of the equipment - the geometry of the structure, material properties, welding and attachment details, etc. - are developed for use in analytic models and in the development of test articles. The results of accidents include the damage to the equipment, such as structural failure, which in turn indicates the design details for which information must be developed.

2b. Develop options for design modifications. Both modifications to existing designs, such as strengthening existing members and providing stronger connections between existing framing members, and clean-sheet designs have been developed. In some instances, potentially effective modifications can be directly inferred from accident consequences. In other instances, extensive analysis is required to determine potentially effective crashworthiness strategies.

3. Determine the effectiveness of existing design and alternative design equipment. From post-accident results, it can be seen how effective the equipment was in preserving the survival space for the occupants and in maintaining the forces and 
decelerations imparted to the occupants to survivable levels. There are typically gaps and uncertainties in the information available from accidents. Analyses and tests are used to fill in the gaps of information available from accidents $(6,7,8,9$, 10, 11). Analytic models and tests, similar to those developed and conducted for the conventional equipment, are used to evaluate the effectiveness of the alternative designs $(6,8,12,13,14)$.

4. Compare the crashworthiness of the alternative designs with the existing designs. For a given collision scenario of concern, comparisons are typically made in terms of the maximum collision speed for which everyone would be expected to survive, or, to support a cost/benefit analysis, in terms of fatalities and injuries as a function of collision speed.

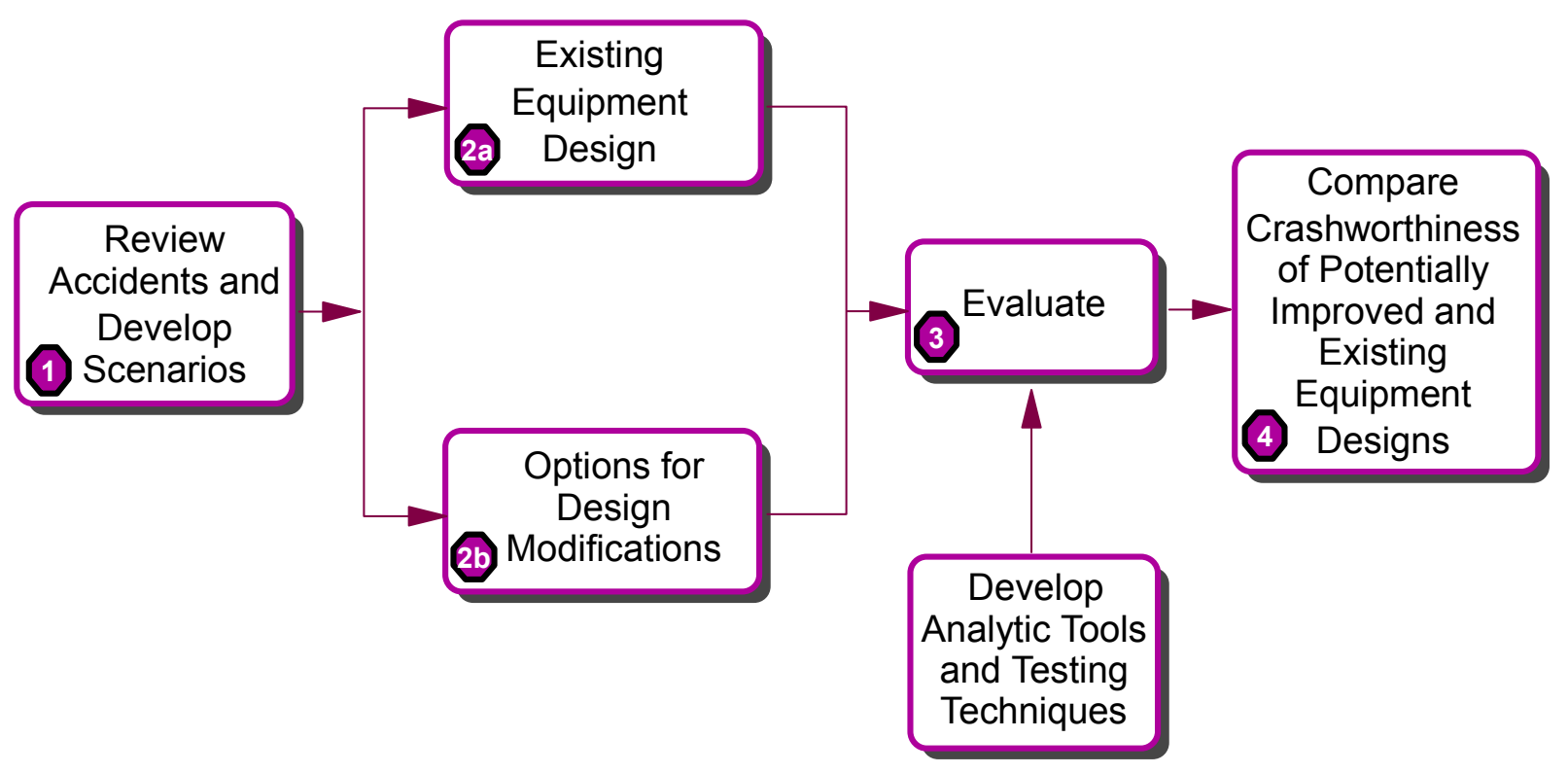

Figure 1. Flow diagram, crashworthiness research principal tasks and utilization of accident information.

In order to evaluate the crashworthiness of existing and alternative designs, analytic tools and testing techniques are developed and refined. Accidents provide information for comparison to analytic model predictions, and help provide some level of assurance of the fitness of the models. The information available from accidents includes observations of the equipment damage, estimates of initial position and speed of the equipment, and measurements of equipment final position. There is also information on occupant injury and fatality, which can be used to estimate the forces and decelerations acting on the occupants. Such information and comparisons are valuable, as rail equipment crashworthiness tests can be prohibitively expensive. While much is often unknown about an accident - such as the precise collision speed and initial conditions for the equipment - analysis results should, at a minimum, qualitatively reproduce the accident consequences for nominally similar conditions. Testing, typically developed to approximate or idealize accident conditions, provides more detailed information for comparison with analysis predictions.

As part of the crashworthiness evaluations, the structural crush behaviors of the individual cars, the dynamic behavior of the trains, and the response of the occupants are evaluated. Structural crush behavior includes the forces required for crushing of the structure, as well as 
the mode, or changing geometry, associated with crushing. The dynamic behavior of the train includes the gross motions of the cars, and the interactions of the cars during a collision. The forces and deceleration imparted to the occupants result from the gross motions of the cars and the occupants' consequent interactions with the interior.

This paper focuses on carbody crush and train collision dynamics. Nearly direct qualitative comparisons of the crush of the equipment and the positions of the cars after an accident can be made with analysis predictions. Detailed evaluation of occupant response requires information on the deceleration of the cars, which is not readily evident from the aftermath of an accident. These decelerations must be calculated using collision dynamics models developed to simulate the accident. While not addressed in detail here, extensive research has been done on the response of occupants during train collisions $(15,16,17,18)$. Focusing on carbody crush and train collision dynamics also allows a broader range of accident conditions to be addressed in this paper.

\subsection{Train Crashworthiness}

The behavior of the train during a collision is influenced by the interactions of the colliding cars, the nature of the coupling between the cars, and the crush behavior of the individual cars. The interactions of the impacting cars can result in one car overriding the other car, resulting in the heavy subframe of the overriding car causing substantial crush of the overriden car. Override of one car by another is often associated with substantial loss of occupant volume, and consequent fatality. The interactions of colliding cars can also lead to the cars laterally deflecting past one another, or potentially remaining engaged with each other. For conventional North American heavy rail passenger equipment, the coupling between cars can lead to lateral buckling of the trainset as a consequence of a collision. When viewed from above, the cars in the train form an accordion pattern. Because the carbody of a typical North American passenger car is essentially uniformly strong along its entire length, the structural damage tends to be focused on the colliding cars, and those cars immediately trailing the colliding cars. Cars away from the colliding cars often remain structurally intact.

Even in a train collision that is nominally head-on - that is the impacting cars are initially inline and their centerlines coincident - one impacting car may override the other or the impacting cars may laterally deflect past each other. The tendency to override or laterally deflect depends upon how the structures of the cars crush and the dynamic responses of the cars in the train to the impact force, as well as the initial conditions of the impact. The mode of crushing of some car structures may effectively form a ramp, leading to vertical or lateral forces that are sufficient to cause override or to cause lateral deflection. The dynamic motions of the car can potentially contribute to misalignment of the underframes, amplifying the tendency toward override or lateral deflection.

A number of severe train collisions in which the impacting vehicles are initially offset or oblique have occurred over the past few years $(19,20,21)$. A collision is oblique when the longitudinal centerlines of the colliding cars are not parallel and is offset when the centerlines are parallel, but not coincident. These conditions typically result in complex trajectories of the impacting equipment. In an oblique collision, momentum transfer instigates vehicle motion in the lateral direction and may initiate movement vertically. The vehicles rotate, yawing about a vertical axis and rolling around a longitudinal axis. These vehicle motions can result in derailment. Contact interaction between the vehicles shifts in location as the cars move and deform. 
While there is significant damage to the ends of the cab cars and locomotives in oblique and offset accidents, the vehicles typically do not engage each other. This tendency toward deflection is a consequence of the long, slender geometry of railroad cab cars and locomotives. Lengths of passenger cars and locomotives are typically 8.5 and 6 times their respective widths. Figure 2 shows an impact force acting on a rigid body with a length 6 times its width. For such a body to deflect (turn away) from the impact force, the lateral component of the impact force needs to be only $17 \%$ or more of the longitudinal force. If the lateral component of the force is less than this value, the body will engage (turn into) the impact force. As a reference situation, gross motion in automotive collisions, in which the impacting bodies have length to width ratios of approximately 2, is much less sensitive to lateral force than in rail equipment collisions. In an automotive collision, the lateral force has a relatively short lever arm to develop a moment that turns the vehicle. The lateral component of the impact force needs to be $50 \%$ or more of the longitudinal force for an automobile to deflect during a collision.

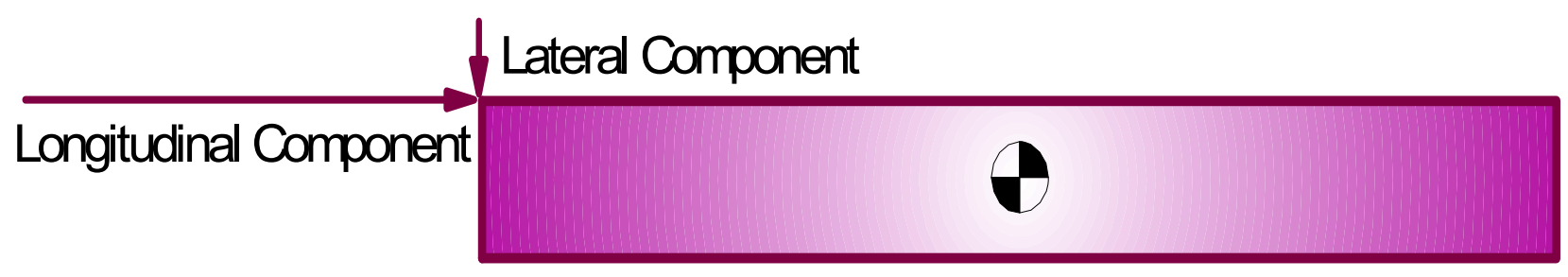

\section{Figure 2. Schematic drawing, minimum lateral force component required to deflect a slender body, drawn approximately to scale.}

During a train-to-train collision, passenger trains will typically buckle out laterally in either a relatively small amplitude sawtooth pattern or in a relatively large amplitude zig-zag pattern. This is due to the linkage behavior of the couplers used on North American passenger equipment. These couplers essentially form a rigid link between cars. When there is a high longitudinal load present, with only a small perturbation, the link formed by the couplers laterally pushes on the ends of the cars. As a result, when the ends of the cars contact, they are laterally offset from each other. The behavior is illustrated schematically in Figure 3.

Once the cars are misaligned, the high longitudinal force acting on one car exerts a significant lateral component on an adjacent car. Consequently, the train will continue to buckle out into the relatively large amplitude zig-zag pattern if there is sufficient energy from the collision. Depending on the severity, this mode may progress until the cars have side-to-side impacts. The results of this behavior have been observed in accidents $(22,23,24)$. The progression of the cars being in-line, to the sawtooth lateral buckling pattern to the zigzag pattern has been simulated (5) with computational models. The progression from in-line to sawtooth buckling has been observed and measured in detail during testing $(8,9)$. 


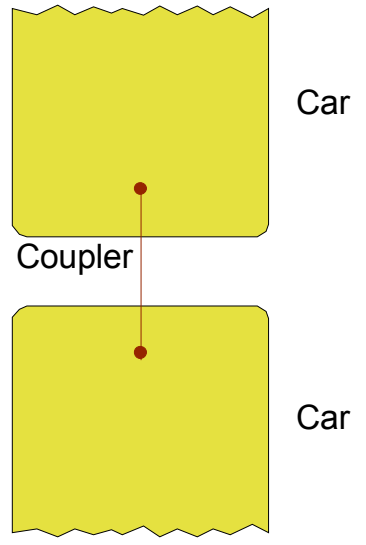

(a)

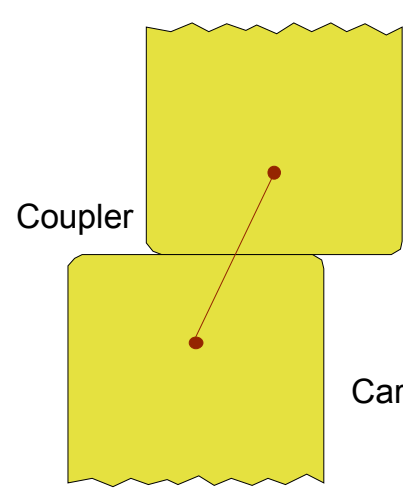

Car

(b)

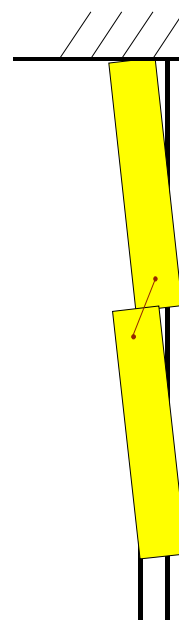

Figure 3. Schematic illustration, sawtooth lateral buckling.

The force/crush characteristics of the cars and locomotives significantly influence which cars are crushed during a collision, as well as the overall behavior of the train. High strength is required to preserve the occupant volume. However, this high strength, with small vertical or lateral misalignments of the cars, can result in significant lateral and vertical forces. The lateral and vertical forces can amplify any tendency toward lateral buckling of the train or toward override. Figure 4 shows the force/crush characteristics developed from measurements made during impact tests of a single passenger car into a fixed barrier and of two coupled passenger cars into a fixed barrier $(7,8,9)$. Both of these curves have high initial peak loads followed by significantly lower loads, which are approximately constant, for continued crush. Similar crush curves have been developed for locomotives $(25,26)$, and these crush curves are also characterized by high initial loads followed by significantly lower loads.

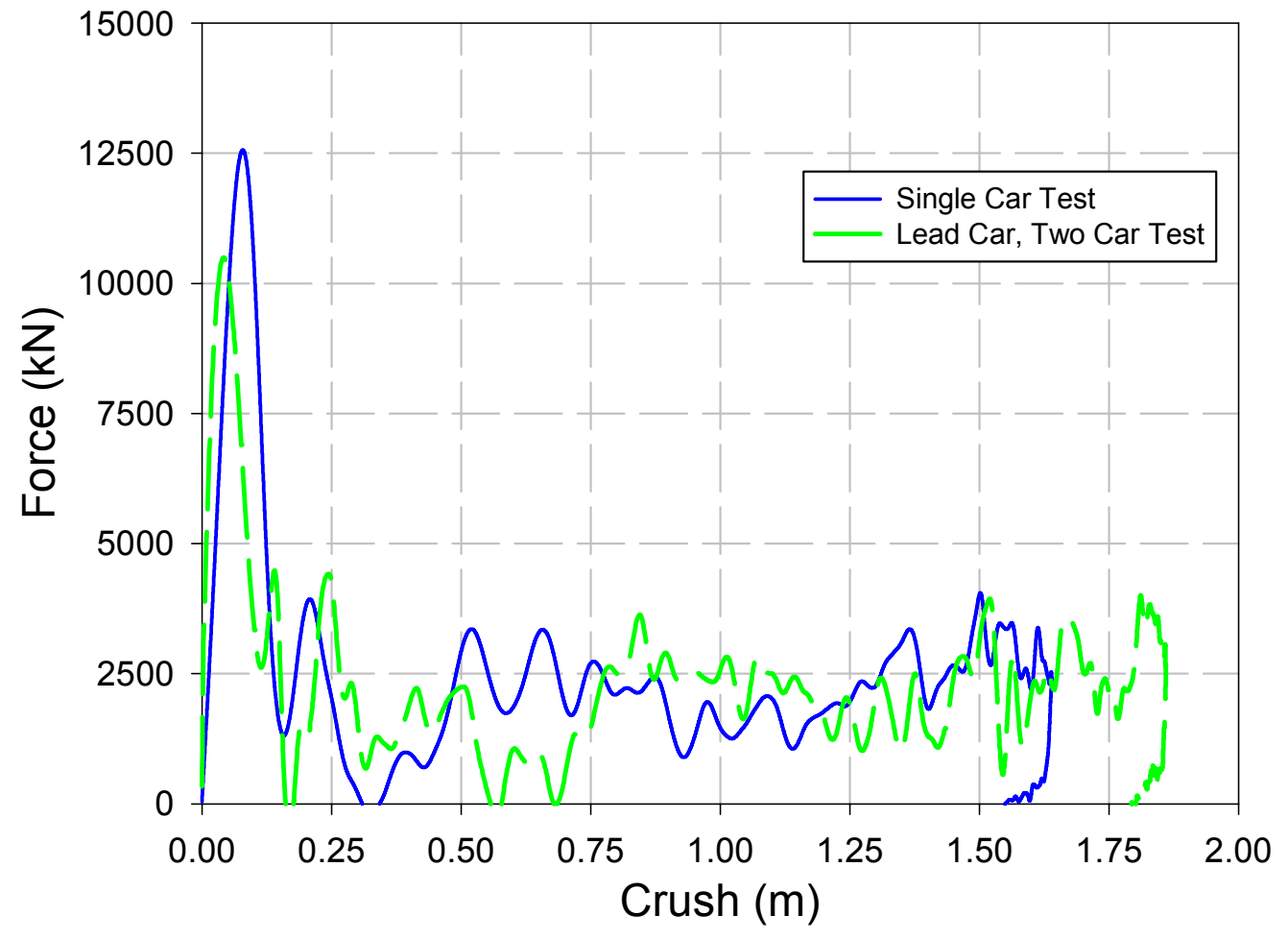

Figure 4. Force/crush curves, typical U.S. passenger equipment. 
One implication of the force/crush characteristic shown in Figure 4 is that the crush will be focused on the colliding cars. If two trains, which are made up of cars with the crush characteristics shown in Figure 4, collide, at best only the two colliding cars will crush. Indeed, only one of the colliding cars may crush if the other colliding car has a marginally greater peak crush load. This is principally owing to the inability of a colliding car to push back with sufficient force to crush the car behind it. In the test of two coupled cars impacting with a fixed barrier $(8,9)$, the lead car sustained significant structural damage - its length was reduced by nearly two meters - while the front end of the trailing car sustained only minor scarring due to the direct contact with the trailing end of the lead car. The most force the car ahead can exert is the lower crush load, while the car behind can apply up to the peak load. There is often little damage to the trailing cars in train collisions of typical U.S. passenger rail equipment.

It has been shown that significant increases in crashworthiness can be achieved if the cars of a train have an increasing force/crush characteristic, i.e., the more the car is crushed, the greater the load that is required. An increasing force/crush characteristic can result in the structural crush being distributed among the cars of the train, potentially just crushing the unoccupied vestibules and better preserving the occupied volumes $(27,28,29,30)$.

\section{ACCIDENTS}

This paper includes descriptions of six passenger train collisions and three derailments. Computer simulations have been developed for three of the collisions, and are referenced. Qualitative comparisons with analyses results have been made for two of the collisions. One of the collisions is currently under evaluation, and efforts are being made to determine the likely decelerations experienced by the occupants. The derailments are described more briefly than the collisions, as detailed information on how passengers are injured in such accidents has not yet been developed.

Passenger train accidents can occur under a wide range of circumstances, but those that can be mitigated by crashworthiness features of the train can be placed into three broad categories:

1. Collisions with another train

2. Collisions with objects, such as a grade crossing collision

3. Single train events, such as a derailment

Further classifications can be made within each of these categories. For example, significant differences may be expected for a locomotive led train colliding with another locomotive led train than for a locomotive led train colliding with a cab car led train. Track route alignment can also significantly influence the consequences of a collision; the consequences of a head-on collision on tangent track may be expected to be significantly different from an oblique collision at a switch. Similarly, the consequences of a grade crossing collision with a heavy highway truck are likely to be significantly different from a grade crossing collision with an automobile. For all accident types, the collision speed can also profoundly influence the consequences of the collision. Placing the accidents into categories allows calculation of the likelihood of that collision category as well as the development of strategies for protecting the occupants in that collision category. 


\subsection{Collisions with Another Train}

Train to train collisions include collisions between a passenger train and a freight train, as well as collisions between a cab car led train and a locomotive led train. Four accidents are described in this section:

1. Syracuse, New York, February 5, 2001

2. Bourbonnais, Illinois, March 15, 1999

3. Secaucus, New Jersey, February 9, 1996 (19)

4. Silver Spring, Maryland, February 16, 1996 (20)

In the first accident, an inter-city passenger train overtook and rear-ended a freight train, with a closing speed of approximately $48 \mathrm{kph}(30 \mathrm{mph})$. The investigation of this accident includes efforts to determine the likely causes of passenger injuries. As this accident just recently took place, efforts are ongoing to reconstruct the motions of the cars, the resulting motions of the occupants, and the causes of occupant injuries. In the second accident, an intercity passenger train collided with a highway vehicle, was forced down a siding, and subsequently collided with several standing loaded freight cars. Qualitative comparisons with analytic modeling have been made. In the third and fourth accidents, a cab car led commuter train collided with a locomotive-led train at a switch. The initial impact occurred while one of the lead vehicles was traversing a switch, resulting in an oblique angle between the lead vehicles. Detailed simulations of the third accident have been developed and used to evaluate the potential effectiveness of structural modifications to the cab car $(31,32)$. Like the second accident listed, qualitative comparisons with analytic modeling have been made for the fourth accident.

\subsubsection{Syracuse, New York, February 5, 2001}

At approximately 11:40 am on Monday, February 5, 2001 an intercity passenger train rearended a freight train, approximately two miles east of the Syracuse, New York train station on Track 1 . The freight train was traveling east at approximately $11 \mathrm{kph}(7 \mathrm{mph})$, and at the time of impact, the passenger train was also traveling east, at a speed between 56 and $68 \mathrm{kph}$ (35 and $42 \mathrm{mph}$ ). The closing speed at impact was between 45 and $56 \mathrm{kph}$ (28 and $35 \mathrm{mph}$ ). The passenger train was on the exit spiral of a 1.5-degree curve, while the trailing cars of the freight train were on tangent track. The point of impact was close to the transition point between the spiral and tangent track. Ten people aboard the passenger train were seriously injured, including a female passenger with a broken femur, and a male passenger with a broken wrist and broken ankle. About fifty passengers received less serious injuries, e.g., cuts and bruises. No one on the freight train was injured.

Figure 5 shows a post-accident schematic. The passenger train was made up of two General Motors/Electro-Motive Division F-40ph locomotives, a coach/dinette car, and four coach cars. Both locomotives were equipped with transit-style ribs on the anti-climber on the short-hood end. The freight train was made up of 88 loaded cars, four empty cars, and two locomotives. The trailing cars of the freight train were bulkhead flatcars carrying lumber. The last car of the freight train - the impacted car - was carrying a full load of framing lumber. This car was equipped with a hydraulic draft-cushioning device. At least two more cars of this type and load were ahead of the last car.

There was very little structural damage to the passenger cars. There was some damage to the flexible bellows between the cars closer to the lead end of the train, associated with the sawtooth lateral buckling of the first four passenger cars. There was also some scarring of the sides of the couplers and their lateral bump stops, also associated with the sawtooth buckling 
of the cars. The freight cars remained in-line, and the track under them did not buckle. The hydraulic cushioning devices may have helped to prevent the cars from laterally buckling, as well as the longer shanks of the freight couplers (compared with passenger couplers) and the greater weight of the freight cars.

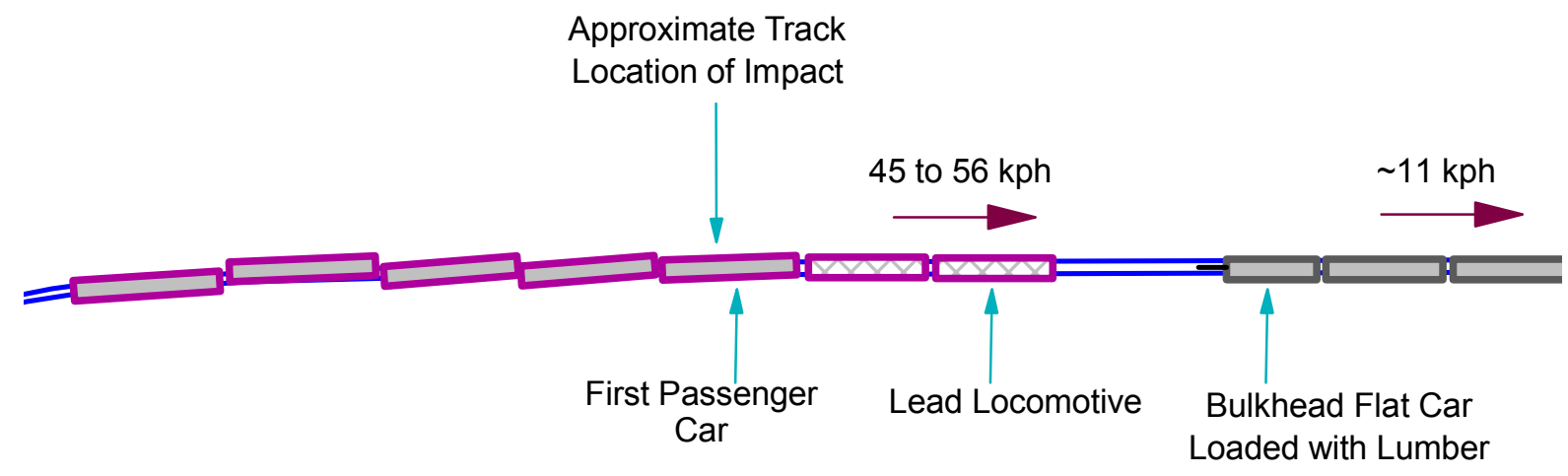

Figure 5. Post-collision schematic drawing, rear-end collision of a freight train by an inter-city passenger train, Syracuse, New York.

Figure 6 shows post-accident photographs of the inter-city passenger train's lead locomotive and the freight train's trailing bulkhead flatcar. It appears that crushing and displacing of the lumber on the loaded bulkhead flatcar absorbed most of the collision energy. The hydraulic cushioning devices on the trailing cars of the freight train also probably helped to dissipate some of the collision energy. (In effect, it appears that the hydraulic cushioning device and the lumber acted as a crash energy management system.) The body and lading of the bulkhead flatcar was crushed approximately $1.8 \mathrm{~m}$ (6 feet), from the trailing end of the carbody up to the trailing axle of the trailing truck. The draft sill and coupler of the bulkhead flatcar remained essentially intact, with the body and lading stripped off. The draft sill and coupler of the bulkhead flatcar acted as a battering ram which tore through the coupler and draft-gear box of the locomotive, which hang beneath the main sill structure of the locomotive. The coupler and the end of the draft sill of the flatcar impacted the front and top of the lead traction motor and front of the body bolster, helping to pry the truck from the locomotive and to push the truck back into the fuel tank. A lug on the lead truck punctured the fuel tank, causing a hole about the size of a baseball. The body of the locomotive began to climb the bulkhead flatcar, as the flatcar was crushing. Grooves from the ribs on the anti-climber can be seen on the bulkhead of the flatcar, 9 to 10 feet from top of rail. (The locomotive anti-climber normally sits approximately 5 feet above top of rail, at the end of the locomotive above the coupler.) The anti-climber engaged a transverse framing member of the bulkhead, which may have helped to stop the locomotive from climbing the bulkhead flatcar any further. 

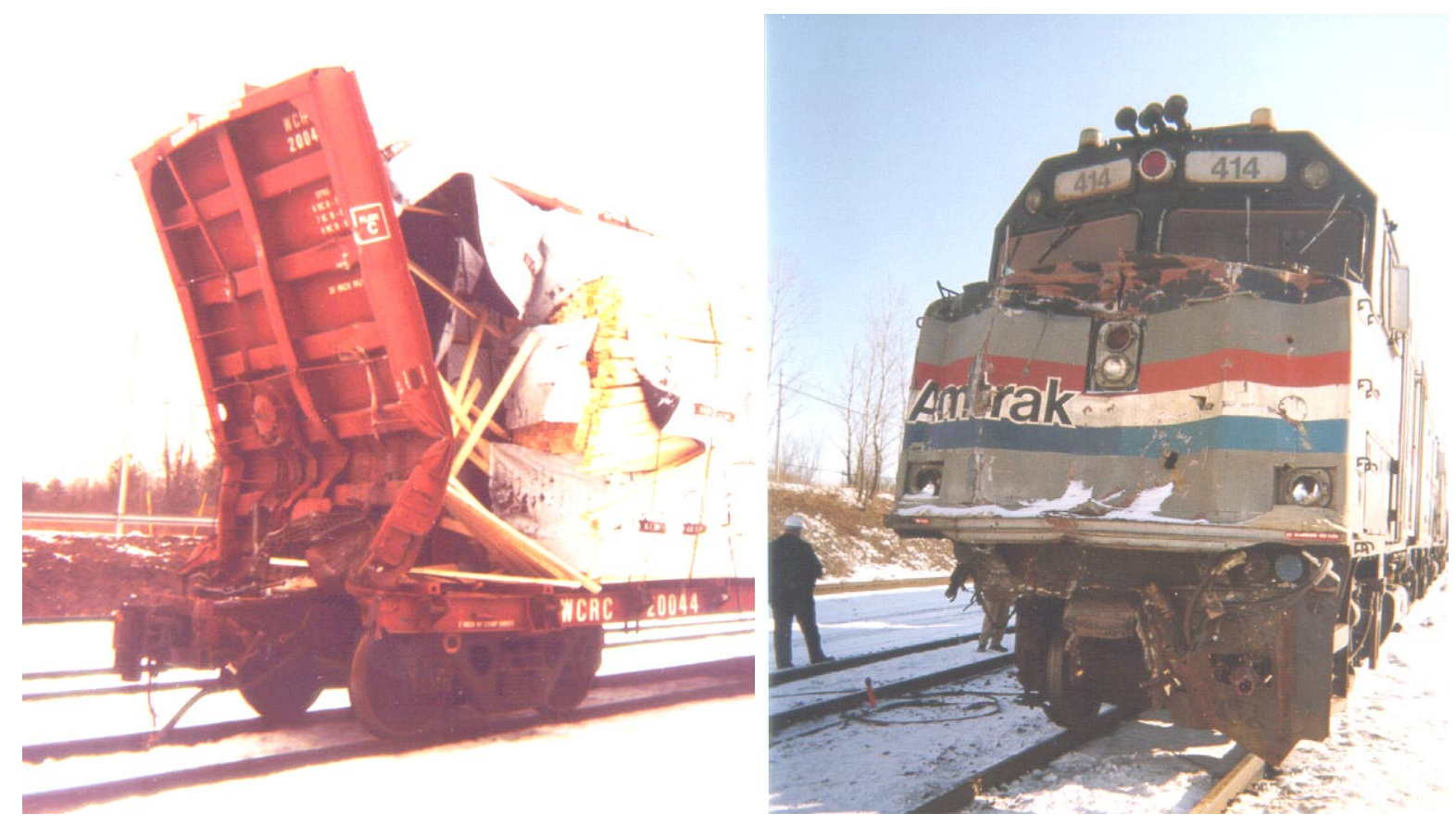

\section{Figure 6. Post-accident photographs, passenger train lead locomotive and freight train trailing loaded bulkhead flatcar, Syracuse, New York collision.}

Efforts are ongoing to reconstruct the trajectories of the cars during this collision, the decelerations of the occupant volumes, and the forces and decelerations imparted to the occupants. The general behavior of the cars - the sawtooth lateral buckling - is consistent with analytic model predictions of train collisions under similar circumstances. It is likely that the environment experienced by the occupants of the passenger cars is similar to the environment measured in the trailing car during the test of two coupled cars impacting with a fixed barrier $(8,9)$. The impacting car in this test sustained structural crush, while the trailing car did not. Similarly, in the accident the colliding equipment sustained structural damage, while none of the other equipment did.

\subsubsection{Bourbonnais, Illinois, March 15, 1999}

At approximately 9:47 pm on March 15, 1999, an intercity passenger train traveling at approximately $127 \mathrm{kph}(79 \mathrm{mph})$ struck a highway tractor-trailer truck at a grade crossing, derailed, and then collided with several standing loaded freight cars in a siding. A large fire ensued, fed by the oil and fuel carried by the locomotives. The passenger train was made up of two General Electric Transportation Systems P40 Locomotives, one baggage car, and thirteen bi-level sleeper cars and coaches. The standing freight cars included a gondola car loaded with scrap steel, and a covered hopper car loaded with fly ash. There were 11 fatalities, all of which occurred in the second bi-level car, a sleeper car. There were 122 injuries, ranging from severe to minor. The train had a total of 216 passengers and crew.

Figure 7 shows a post-collision schematic of the train. Because of the severity of the collision, it is very difficult to infer a likely sequence of events. The collision with the highway tractortrailer likely resulted in little structural damage to the locomotive. The lead locomotive impacted the rear wheel of the trailer. The trailer was loaded with approximately $178 \mathrm{kN}$ (40 kips) of steel rebar, a relatively light load. The principal impact was probably with the loaded freight cars. 


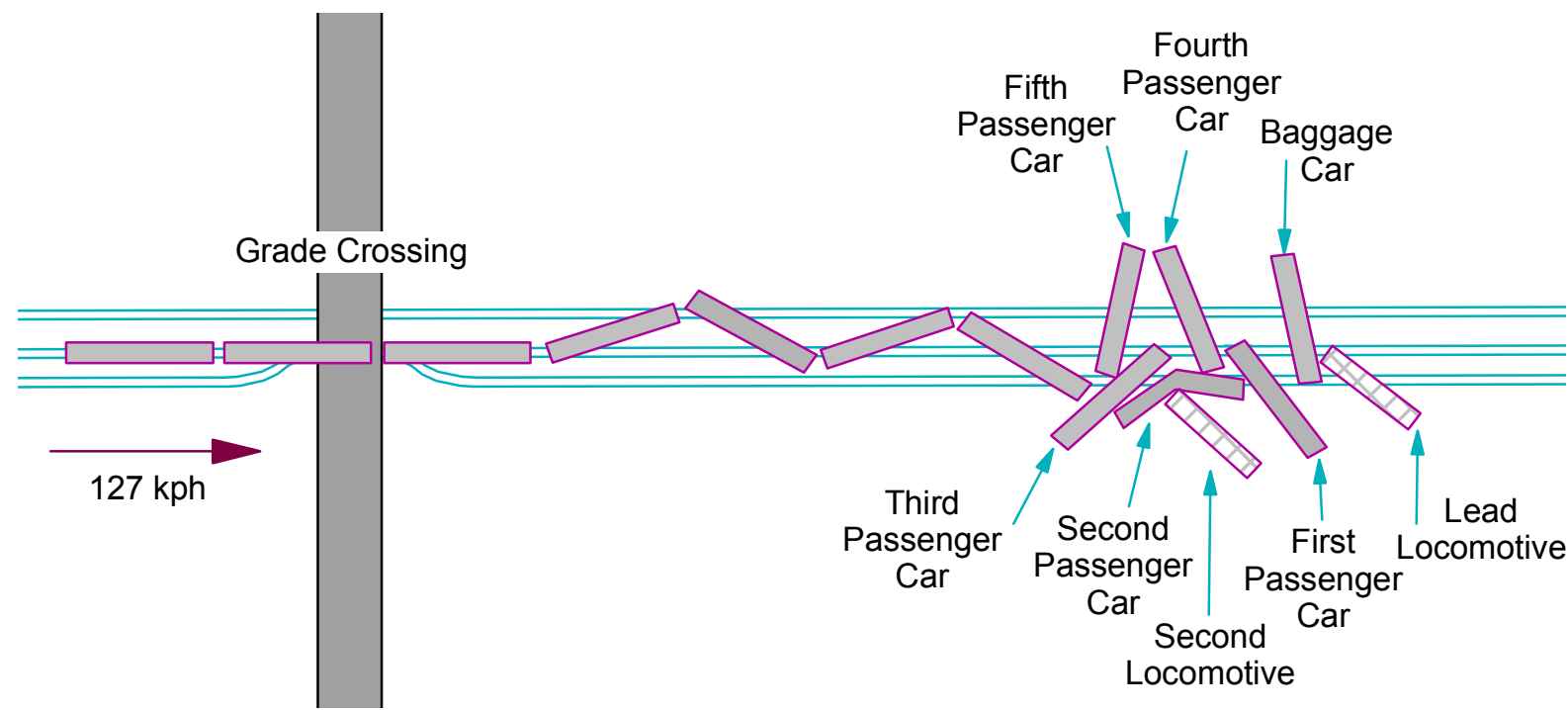

Figure 7. Post-Collision schematic, passenger train collision with highway truck and subsequent collision with standing freight cars, Bourbonnais, Illinois.

Significant structural damage occurred to the first and second locomotives, which are shown in Figures 8 and 9 respectively. The lead locomotive had significant damage on the left side, particularly near the rear. The fuel tank in this locomotive is integral with the center portion of the frame, i.e., the side sills between the trucks make up most of the fuel tank. There were several punctures and gashes in the fuel tank. The trailing locomotive was extensively damaged. The equipment in the rear third of the locomotive was stripped off, and the trailing third of the locomotive frame was bent into the shape of a 'W.'

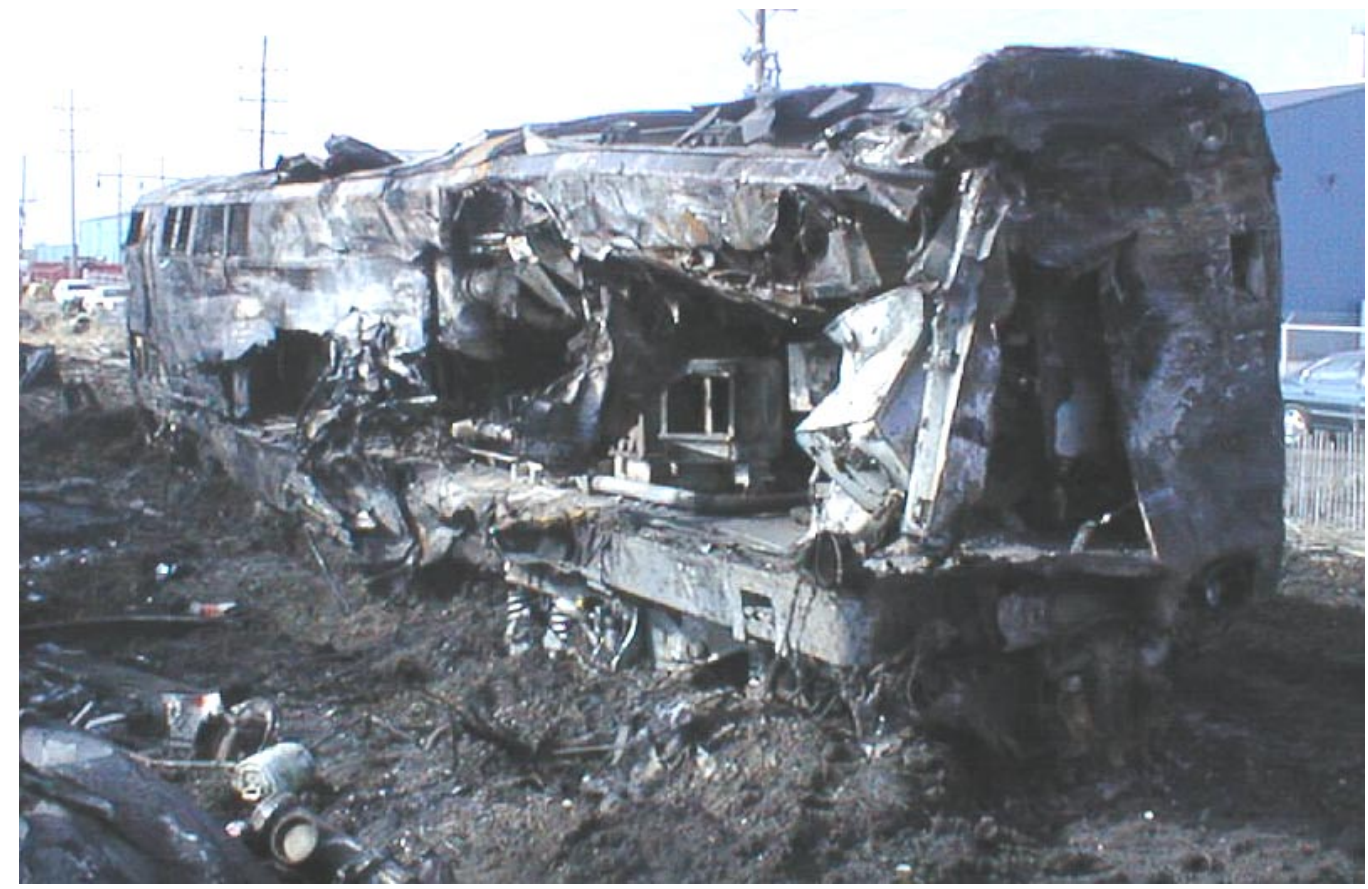

Figure 8. Post-Accident Photograph, Lead Locomotive, Bourbonnais, Illinois Collision. 


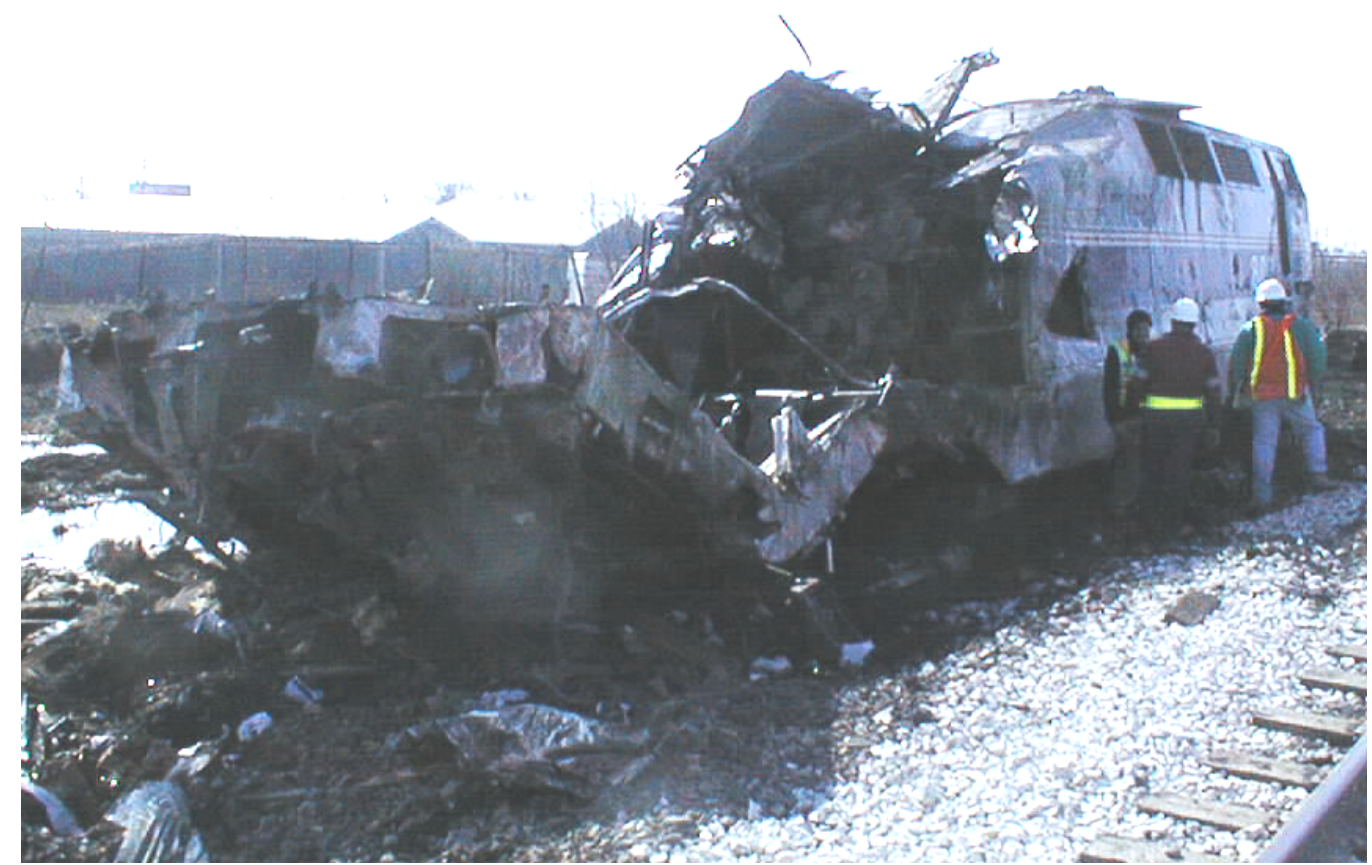

Figure 9. Post-accident photograph, second locomotive, Bourbonnais, Illinois collision.

The most severely damaged passenger car was the second bi-level car, shown in Figure 10. In the pile-up, this car received lateral impacts from several other cars and the second locomotive. The rear of the second locomotive impacted it near the center of what is believed to have been the right side. There was a side-to- side impact with another bi-level car opposite the impact with the locomotive. The front of another bi-level car impacted it on the side near the lead truck.

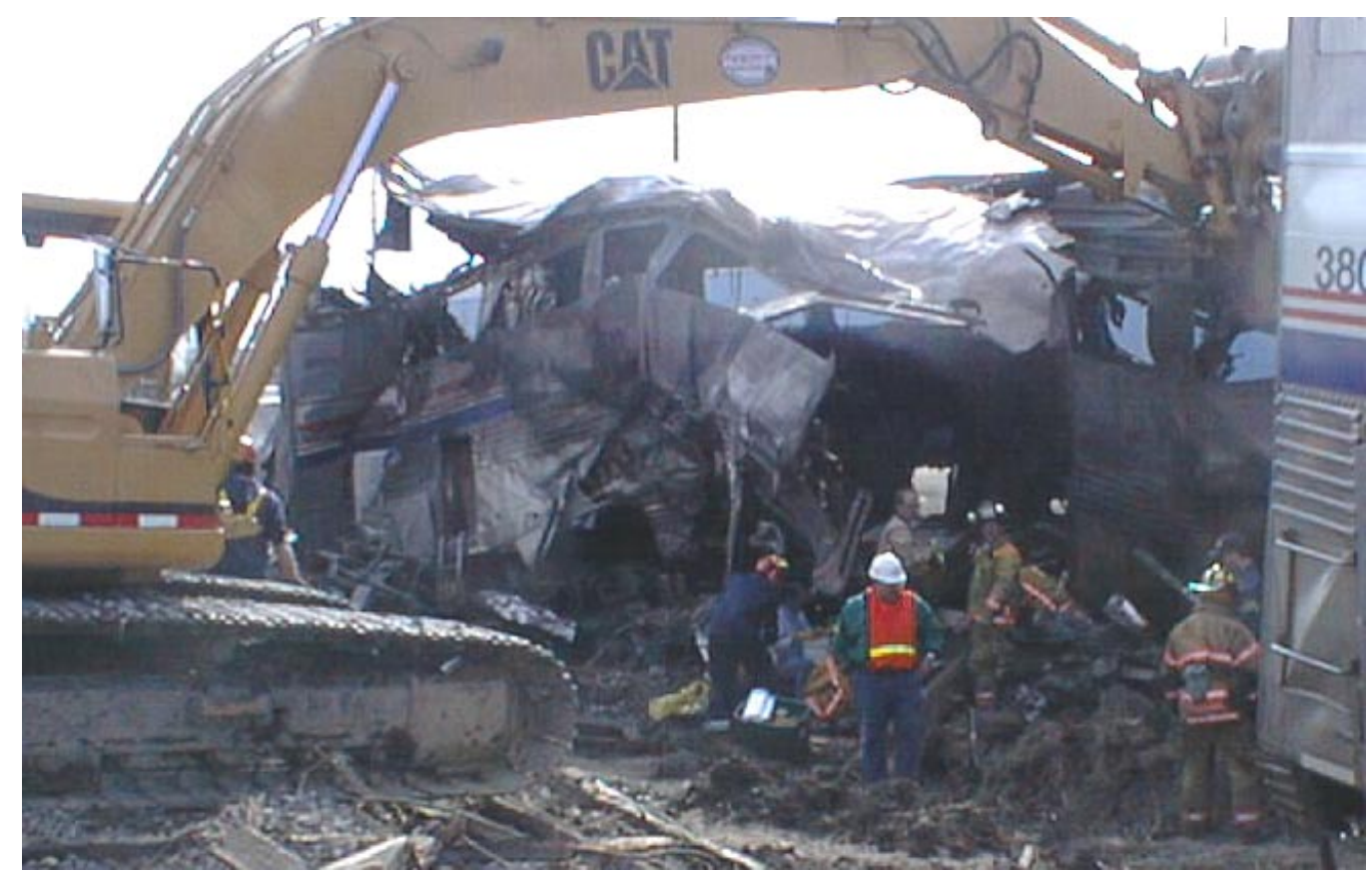

Figure 10. Post-accident photograph, second bi-level passenger car, Bourbonnais, Illinois collision. 
Qualitative comparisons of the consequences of this accident have been made with analysis results. This accident did show large amplitude zigzag buckling for the car closest to the impact, as well as smaller amplitude sawtooth buckling for the intermediate cars in the train. The trailing cars remained in line. The structural damage was focused on the cars closest to the impact point. There was very little structural damage to the fifth passenger car, or to any of the cars behind it.

\subsubsection{Secaucus, New Jersey, February 9, 1996}

On February 9, 1996, the cab car of a commuter train made up of a cab car, four coach cars, and a locomotive, struck the locomotive of another commuter train, made up of a locomotive, five coach cars and a cab car. There were three fatalities: the locomotive operator, the operator of the leading cab car, and a passenger in the same cab car. There were twelve serious injuries, all in the leading cab car.

Figure 11 illustrates a potential sequence of events during the collision, based on conversations with FRA and NTSB officials. It appears that the collision progressed as follows:

1. The cab car was traveling at approximately $29 \mathrm{kph}(18 \mathrm{mph})$ when it struck the front, right corner of the locomotive, which was traveling at approximately $85 \mathrm{kph}$ (53 $\mathrm{mph}$ ) in the opposite direction. Based on the track geometry, the angle between the two vehicles at the instant of impact was approximately $7^{\circ}$. The corner post on the right side of the cab car struck the right side of the locomotive. Both collision posts on the cab car remained in place, though the right post incurred some structural damage. The right corner post was torn away from the cab car. The roof plate from the right side of the cab car broke away and penetrated the window of the locomotive.

2. The cab car raked down the side of the locomotive. The left rail (field side) under the locomotive rolled over and the locomotive derailed.

3. The derailed locomotive pulled the trailing cars off the track. The cab car continued to rake the cars trailing the locomotive, damaging stairwells as it went.

4. Most cars in the locomotive-led consist derailed (the last car may have stayed on the track). Only the cab car derailed in the cab car-led consist. The cab car-led consist was stopped by the collision at the switch. The locomotive-led consist slid to a stop on the ties and ballast. 


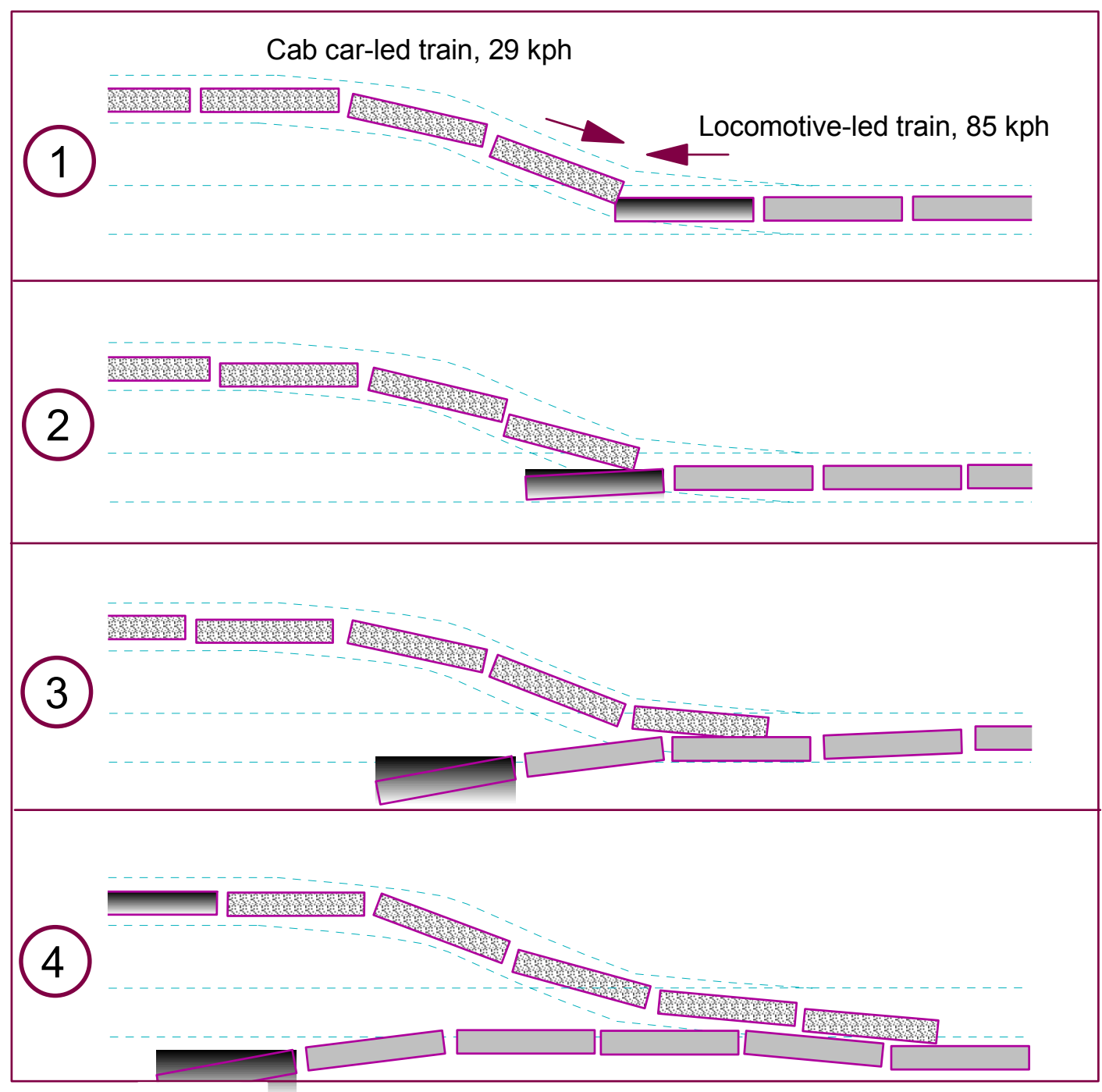

Figure 11. Schematic of Secaucus, New Jersey, cab car/locomotive collision (hypothetical).

Damage occurred principally to the lead vehicles of each of the trains. The lead locomotive was a General Motors/Electro-Motive Division GP40PH-2, rebuilt by Morrison-Knudsen in 1993. Bombardier built the lead cab car, which had a steel underframe and aluminum superstructure.

The roof plate of the cab car penetrated the operator's window of the locomotive. Damage to the hood of the locomotive appeared to be due to the roof plate riding up on the hood and through the window. Some superstructure damage to the front of the locomotive, approximately halfway between the coupler and the side of the locomotive, appeared to have been caused by the front of the cab car. The center sill and main structure of the locomotive remained essentially intact. A post-collision photograph of the locomotive is shown in Figure 12. 


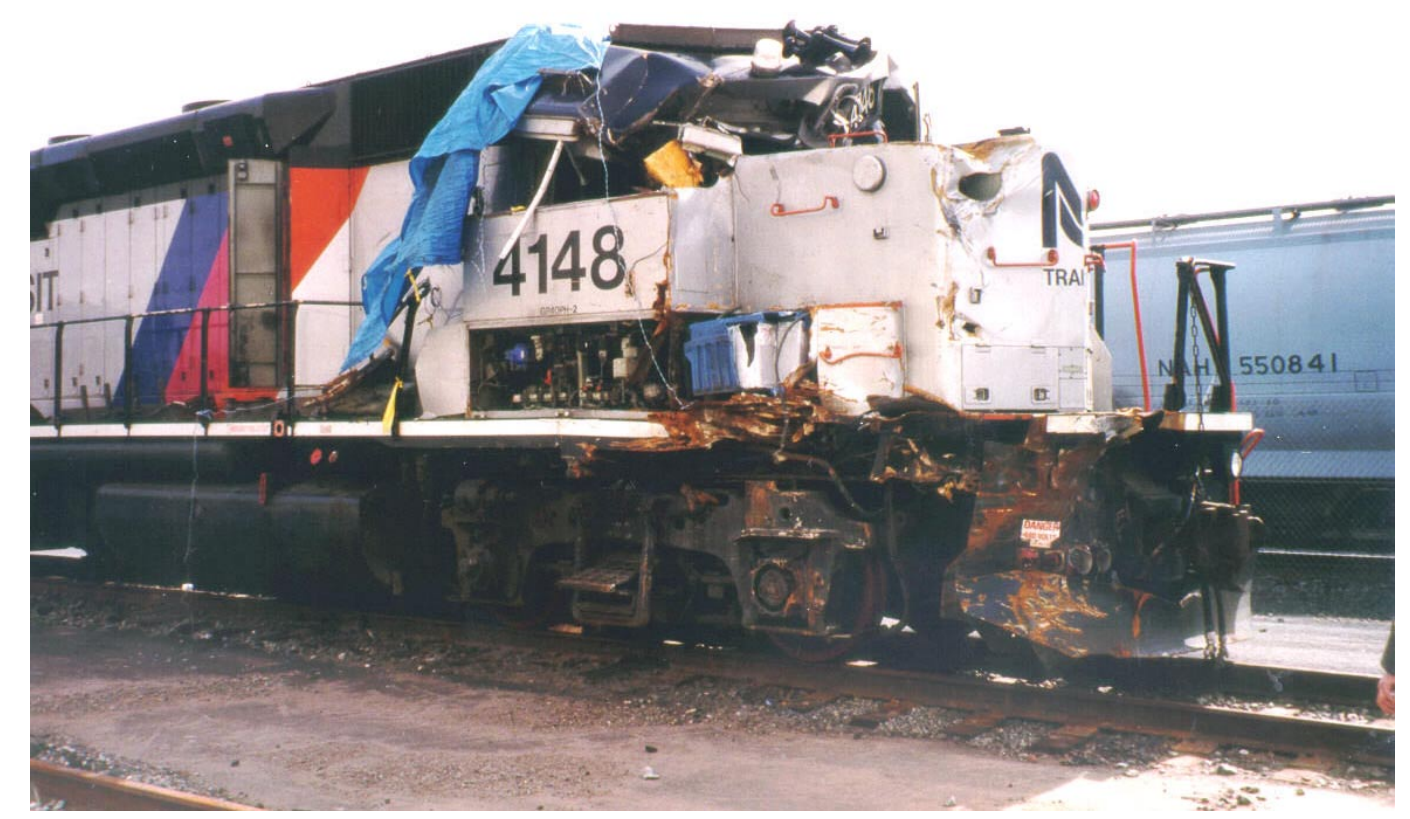

Figure 12. Post-accident photograph, impacted locomotive, Secaucus, New Jersey collision.

Damage to the lead cab car includes crushing of the right, front corner of the car from the end of the car to the body bolster. This area includes the operator's compartment and approximately five rows of seats. The right (track-side) collision post incurred substantial damage: there are several large cracks in and around the attachment point. This damage may have occurred when the end of the transverse floor member was torn off in the initial collision with the locomotive. The collision post itself may not have been loaded directly. The corner post and a portion of the roof plate were separated from the cab car. A post-collision photograph of the cab car is shown in Figure 13.

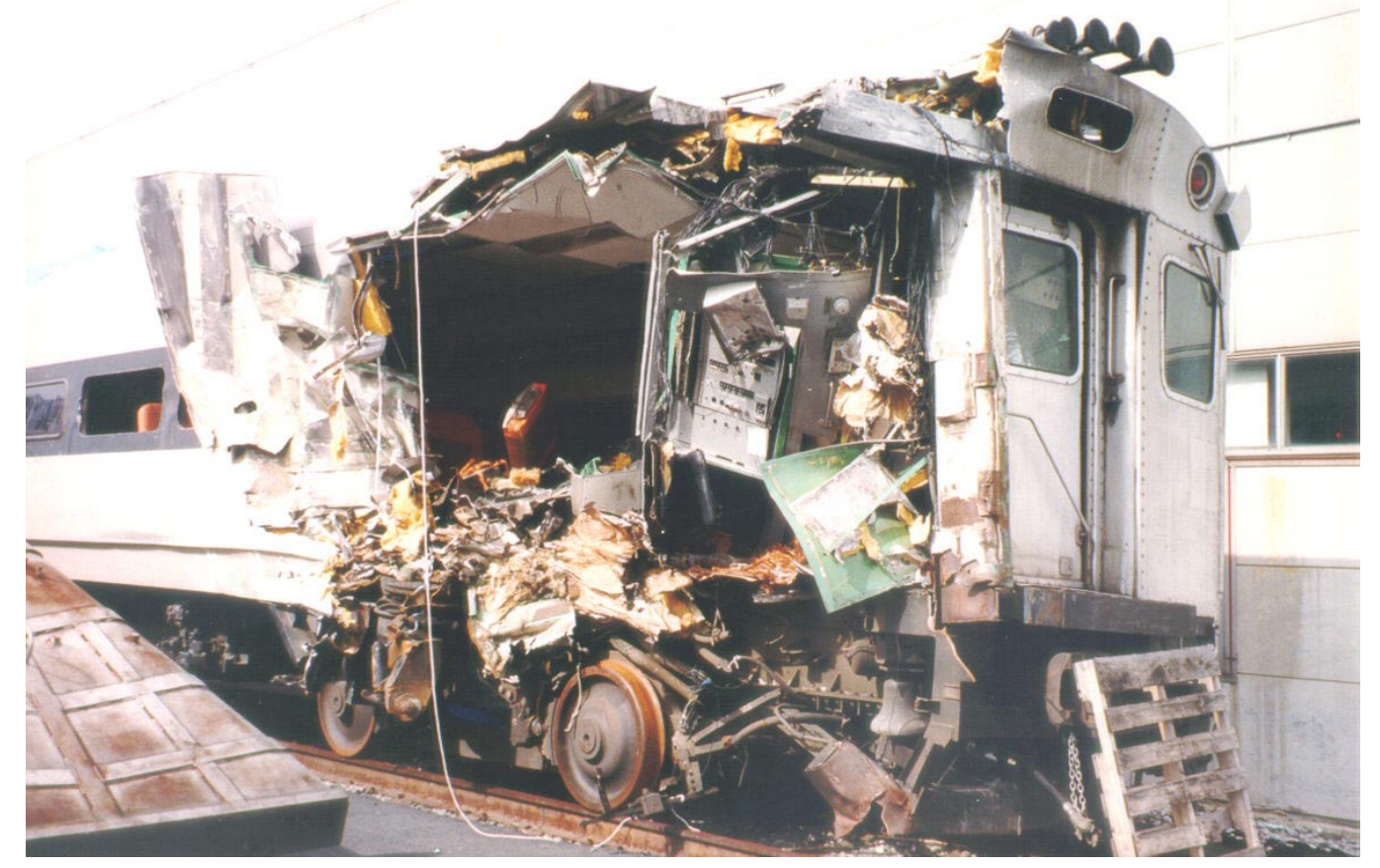

Figure 13. Post-accident photograph, lead cab car, Secaucus, New Jersey collision. 
Seat frames in the cab car were crushed or missing from the body bolster forward on the side of impact. The seats across the aisle from the crushed seats also incurred substantial damage, due to debris from the collision and damage to the floor. In all, approximately 25 seat positions were destroyed during the collision. In areas away from the structurally damaged sections, the seat frames and luggage racks generally remained intact.

The typical North American passenger cab car structure consists of an underframe, an end structure and a body shell. The underframe consists of four longitudinal members: the center sill, draft sill and two side sills, and two body bolsters, which laterally connect the center sill, draft sill, and two side sills. The end structure consists of an end beam (or buffer wing), two vertical collision posts and two vertical corner posts. The structural members with the largest cross-sectional areas are the center sill, the draft sill, and the body bolster. The main cab car structural members are depicted schematically in Figure 14.

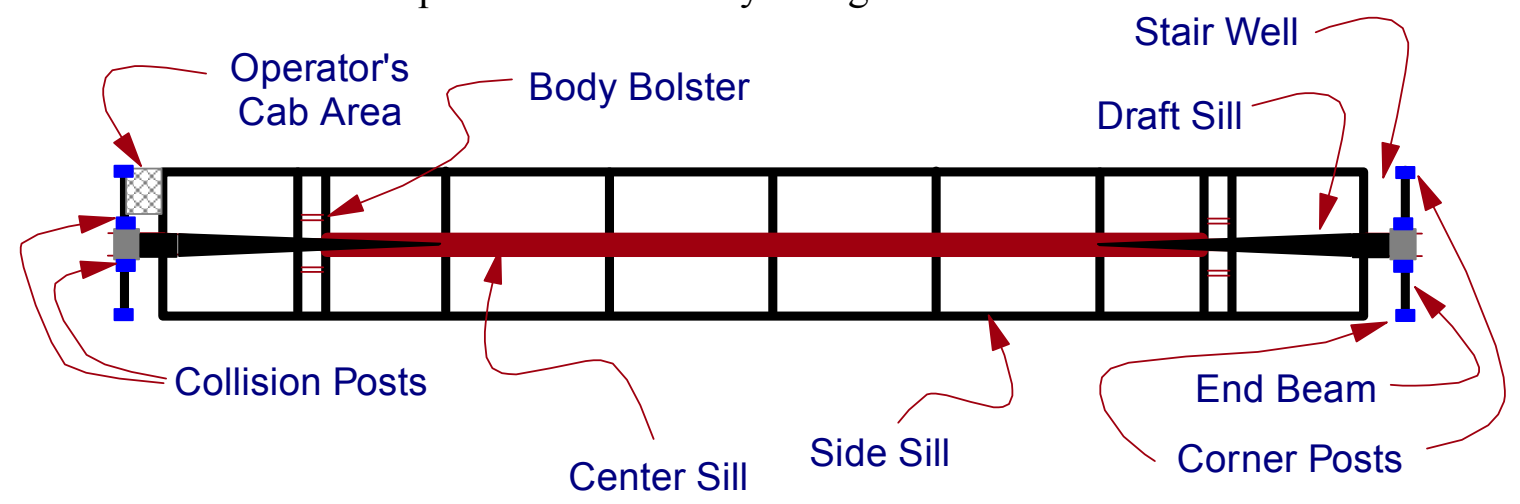

Figure 14. Schematic of typical cab car structural members, plan view.

The main structural elements (i.e., body bolster, center sill, draft sill) of the cab car in the Secaucus collision remained essentially intact. The structural damage consisted principally of crushing of one side of the vehicle, from the end beam to the body bolster longitudinally, and from side sill to the roof plate vertically. There was significant damage to the impacted corner post, end beam and side sill. The end beam failed near the base of the collision post. Figure 15 schematically illustrates the structural damage to the frame of the cab car.

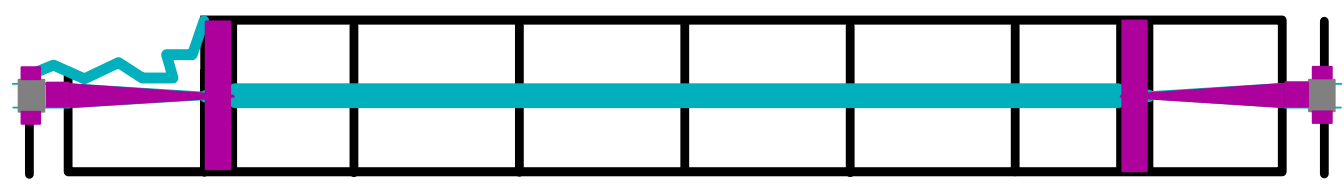

Figure 15. Schematic of underframe collision damage, Secaucus, New Jersey collision.

Car crush and train collision dynamics models have been developed to simulate the trajectories and crush of the equipment involved during this oblique collision $(31,32)$. These models have been exercised to evaluate the potential benefit of modifications to the end beam. By increasing the maximum longitudinal load that the end beam can support at the corner of the car from 667 to $3336 \mathrm{kN}$ (150 to $750 \mathrm{kips}$ ), the maximum safe collision speed for the operator - the maximum collision speed for which the operator could be expected to survive can be increased from 14.5 to $29 \mathrm{kph}$ ( 9 to $18 \mathrm{mph}$ ). This increase in end beam strength correspondingly increases the amount of energy that can be absorbed by the crush of the end beam. The maximum safe speed for the passengers - the maximum collision speed for which all the passengers, but not the operator, could be expected to survive - increases from $31 \mathrm{kph}$ 
to $51 \mathrm{kph}$ (19 to $32 \mathrm{mph}$ ). Efforts are planned to evaluate the potential effectives of a completely re-designed end structure.

\subsubsection{Silver Spring, Maryland, February 16, 1996}

On February 16, 1996, a cab-car led commuter train, with two coach cars and a locomotive collided nearly head-on with an intercity train made up of two locomotives and 15 baggage and passenger cars. The lead locomotive of the inter-city train was just starting through a switch to an adjacent track, traveling at approximately $48 \mathrm{kph}(30 \mathrm{mph})$, when it struck the commuter train, traveling at approximately $64 \mathrm{kph}(40 \mathrm{mph})$ in the opposite direction. There were eleven fatalities and twenty-six injured passengers, all on the commuter train. Three of the fatalities are believed to be the result of the collision, and eight are believed to be the result of the post-collision fire.

It appears that the collision progressed in several steps, which are illustrated Figure 16:

1. The lead cab car of the commuter train struck the front of the lead locomotive of the inter-city train. The locomotive of the inter-city train had just started to traverse a switch, and consequently the cab car and locomotive were misaligned when the collision started. The coupler of the cab car was approximately aligned with the side of the locomotive. The cab car subsequently raked along side of the locomotive, tearing off and rupturing the locomotive fuel tank. The difference in main structure heights between the locomotive and the cab car allowed the cab car underframe to shear off the equipment hung beneath the underframe of the locomotive and the locomotive underframe to tear the carbody skin above the side sill from the cab car.

2. The impact with the cab car nearly aligned the lead locomotive of the inter-city train with the direction of the track, but displaced the cab car laterally (to the right in the figure). The front of the lead locomotive of the inter-city train struck the front of the second car in the commuter train. This interaction started the front of the lead locomotive of the inter-city train moving to the side (toward the left in the figure)

3. The lead locomotive of the inter-city train separated from its lead truck and began to plow the earth while the second locomotive continues to push. The second locomotive of the inter-city train, in combination with the (small) lateral displacement due to the interaction with the second car of the commuter train, acted to turn the lead locomotive of the inter-city train clockwise. The impact between the lead locomotive of the inter-city train and the second car of the commuter train, in combination with the commuter train being pushed by its locomotive, resulted in the third car of the commuter train derailing (to the right in the figure).

4. The front of the lead locomotive of the inter-city train continued to plow; the couplers between the lead and second locomotives broke. The lead locomotive eventually turned clockwise approximately $270^{\circ}$. The remaining equipment slid to a stop. 


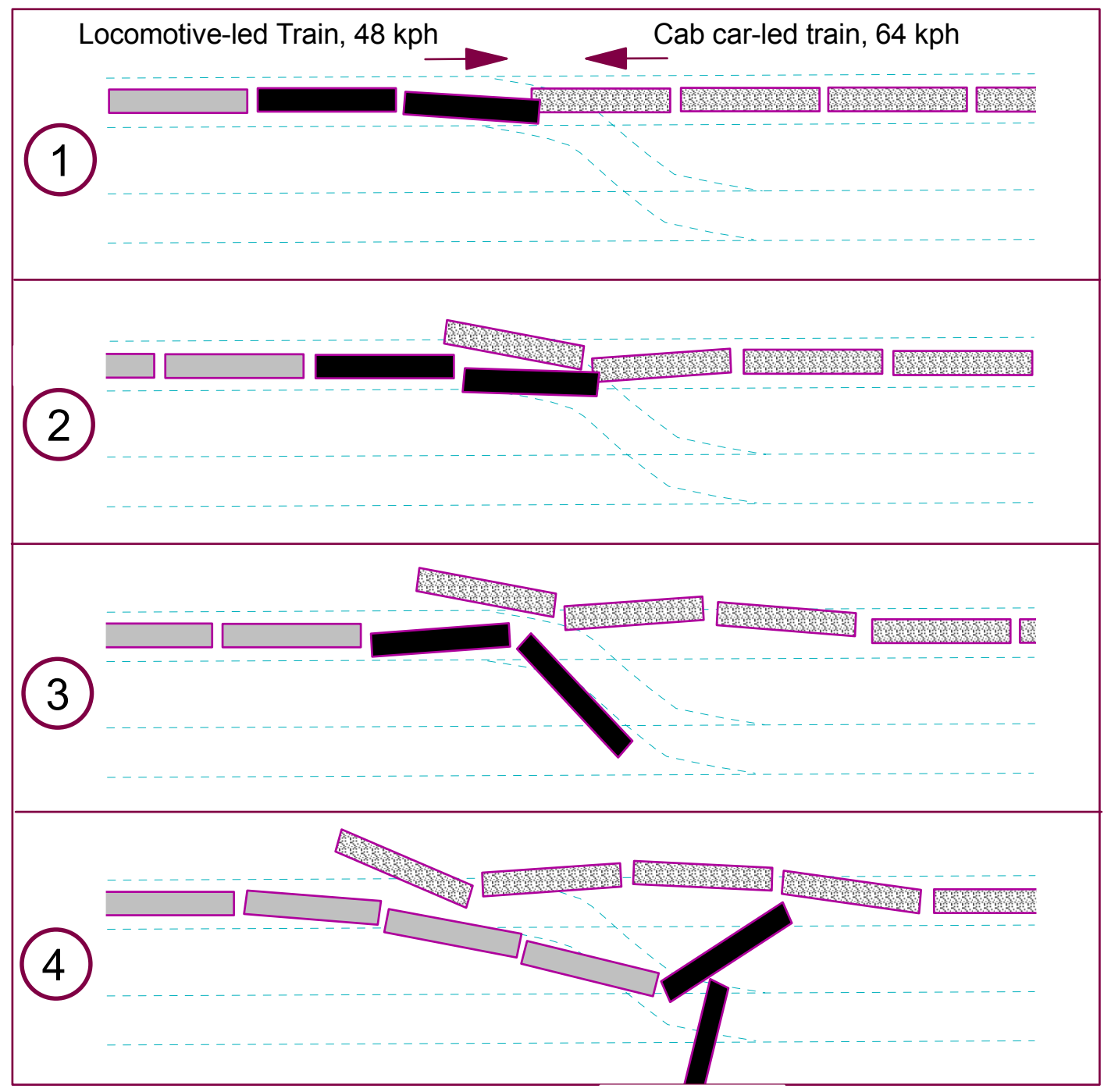

Figure 16. Schematic of Silver Spring, Maryland, cab car/locomotive collision (hypothetical).

A post-collision photograph of the cab car is shown in Figure 17. In the photo, the cab car is sitting on a flatcar and the windows visible in the photo are on the far-side of the cab car. The wire frames in the photo are the metal remains of the seat frames and other interior fixtures; essentially all non-metal interior components were destroyed in the fire. There is extensive fire damage to the car, in addition to the collision damage. The structural damage to the second commuter car is similar to the damage done to the cab car, although there is little fire damage to the second car. The left side of the second car is crushed from the end of the car to the body bolster, although both collision posts are intact. 


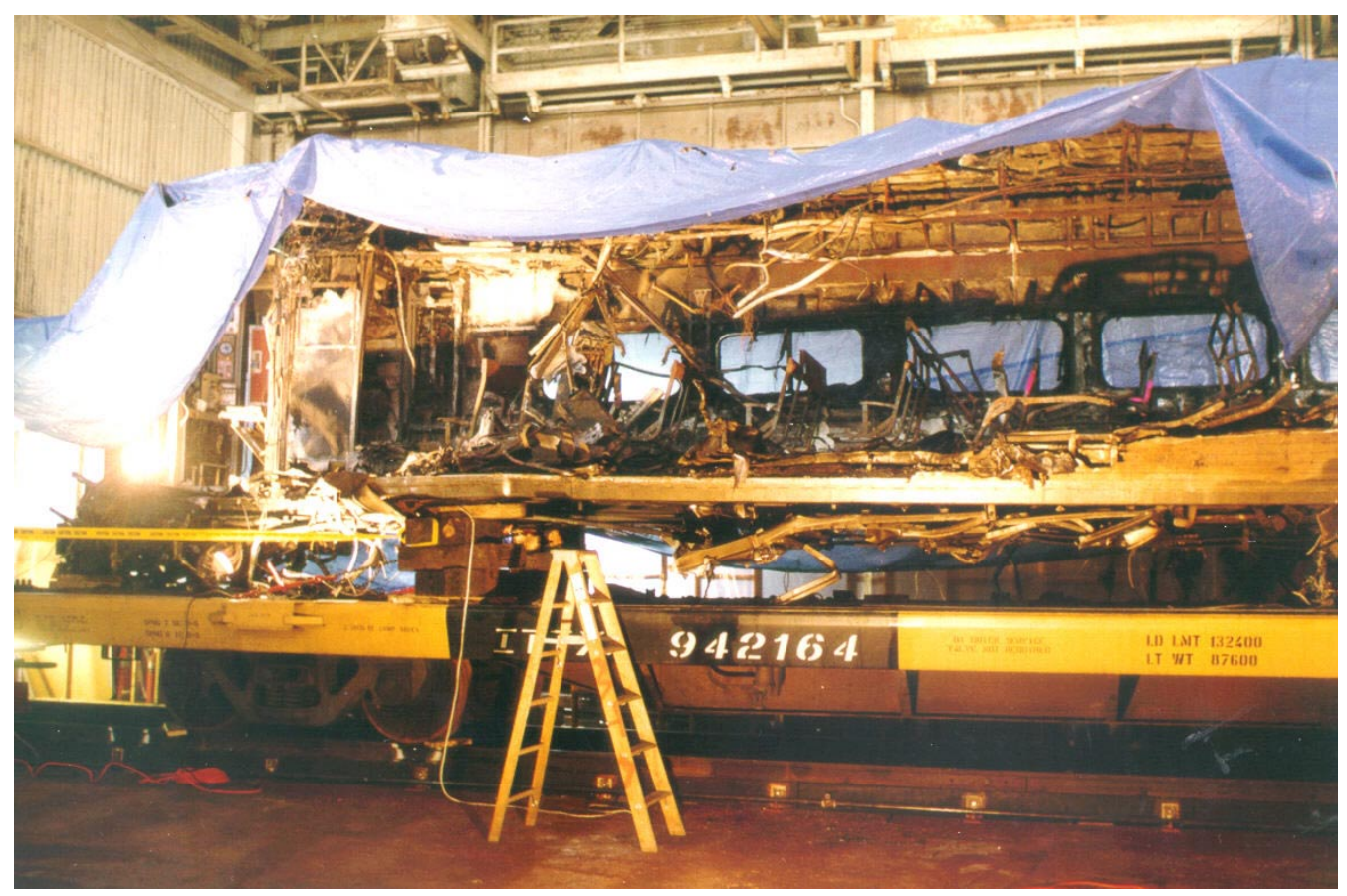

Figure 17. Post-accident photograph, lead cab car, commuter train, Silver Spring, Maryland collision.

The damage done to the lead locomotive of the inter-city train includes puncture of the hood and removal of the equipment hung under the left (track) side of the locomotive, including the fuel tank. There is little damage to any of the main structural components of the locomotive. It is likely that the hood of the locomotive was punctured by the roof plate and corner post of the cab car. The operator's cab remained essentially intact, although both windshields were broken. A post-collision photograph of the lead locomotive is shown in Figure 18.

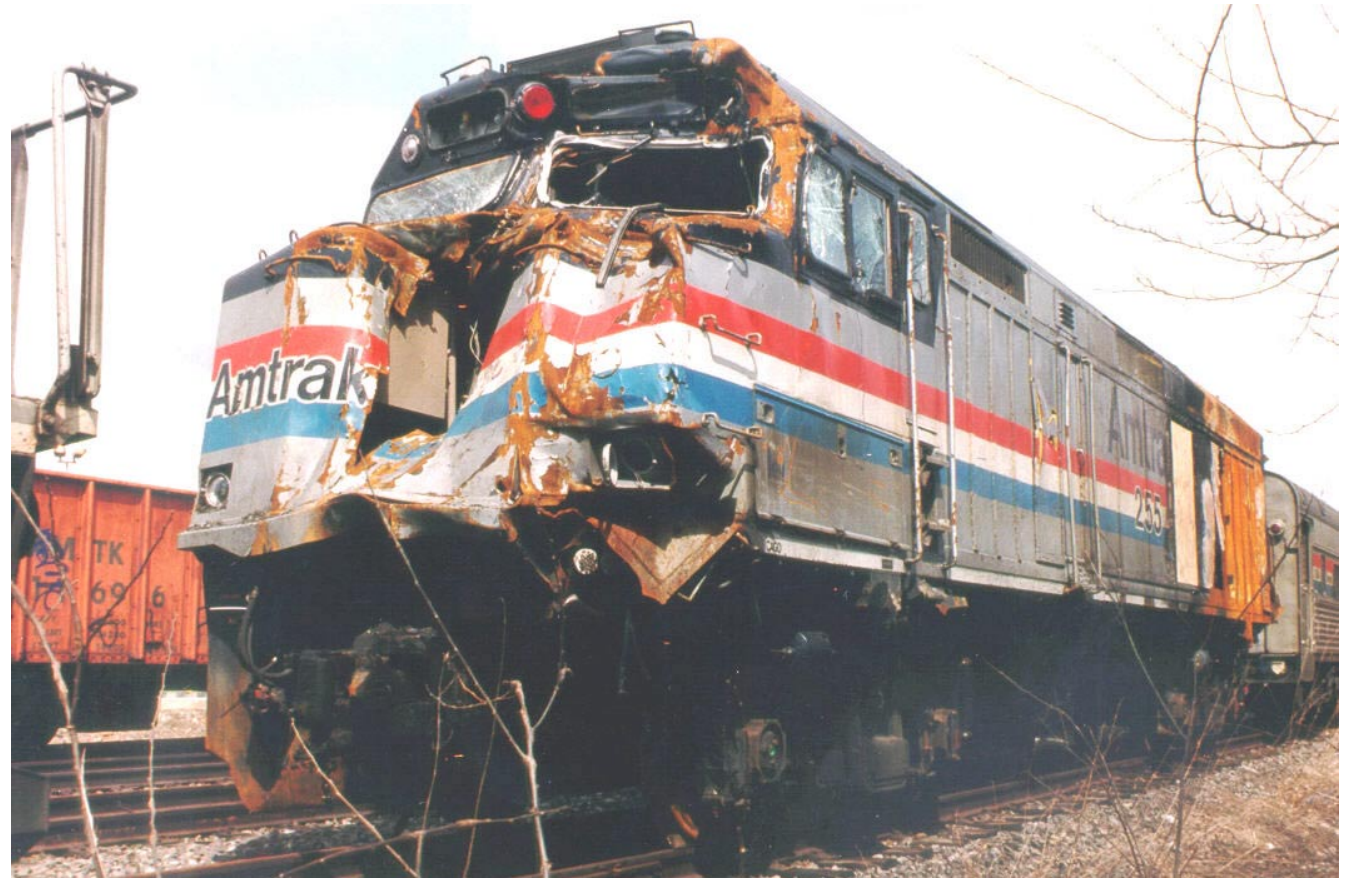

Figure 18. Post-accident photograph, lead locomotive, inter-city train, Silver Spring, Maryland collision. 
Damage to the second locomotive of the inter-city train occurred after the couplers between the two locomotives broke and the rear of the lead locomotive scraped past the side of the second locomotive and when the second locomotive of the inter-city train hit the locomotive of the commuter train, near the end of the collision. The second locomotive of the inter-city train was being run backward. No significant structural damage occurred. Sheet metal damage also occurred at the rear of the second locomotive of the inter-city train, apparently due to the collision with the locomotive of the commuter train.

Models to simulate this accident have not been developed. However, some of the information from this accident was used in developing the model of the Secaucus accident. In the Silver Spring accident, the main structures did engage, at least briefly. Unlike the Secaucus accident, there was damage to the coupler and draft sill of the cab car. Like the Secaucus accident, the impacting locomotive and cab car deflected past each other.

\subsection{Collisions with Objects}

The category of Collisions with Objects includes any collision between a train and something other than a train, such as a collision with highway vehicles at a grade crossing, as well as a collision with a displaced intermodal trailer fouling the right of way. Two accidents are described in this section:

1. Portage, Indiana, June 18, 1998 (33)

2. Selma, North Carolina, May 16, 1994 (21)

In the first accident, a cab car-led commuter train collided with a tractor-tandem trailer carrying coils of steel. In the second accident, a locomotive-led intercity passenger train collided with an out-of-position intermodal trailer on a flatcar. The flatcar was part of an oncoming freight train on the adjacent track. Simulation models of both accidents have been developed in order to evaluate the potential effectiveness of structural modifications.

\subsubsection{Portage, Indiana, June 18, 1998}

On June 18, 1998, a cab car led, two-car multiple-unit commuter train collided with a highway truck trapped at a grade crossing. The highway truck consisted of a tractor with two trailers. The trailers were loaded with coils of sheet steel. The second trailer, the one furthest from the tractor, was stopped on the tracks. The train collided with the second trailer, and during the impact a coil of steel broke free and punctured the end of the car. The train was traveling at a speed between 69 and $109 \mathrm{kph}$ (43 and $68 \mathrm{mph}$ ) when it hit the highway truck. As a result of the collision, three people were killed: a deadheading railroad employee and two passengers. The initial conditions of the accident are shown schematically in Figure 19.

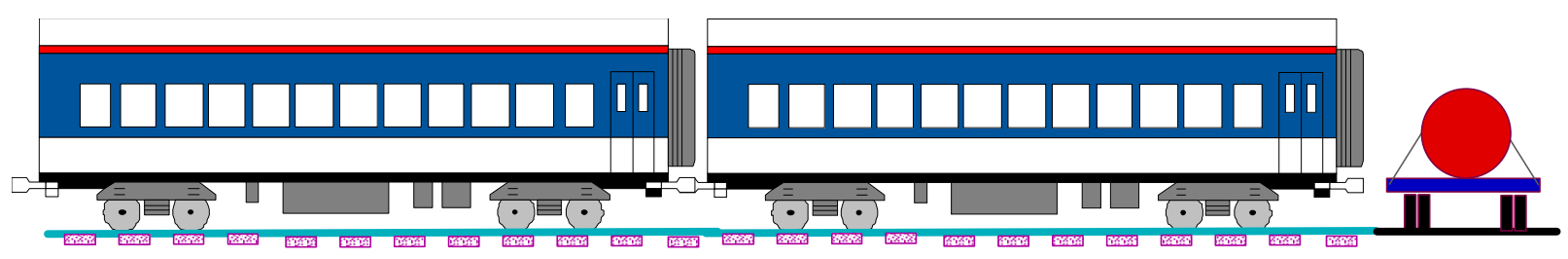

Figure 19. Schematic drawing of Portage, Indiana grade crossing collision.

Figure 20 shows post-accident photographs of the cab car, the highway truck trailer, and the coil of steel. The coil of steel weighed approximately $178 \mathrm{kN}$ (40 kips), and was about $1.8 \mathrm{~m}$ (6 feet) in diameter. It received little damage during the collision. Height of the floor of the trailer was several inches below the height of the floor of the cab car. Owing to the shape of the coil, it moved upward when it hit the end of the cab car. As shown in the photograph, the 
coil of steel punctured the end of the cab car. The coil stopped inside the cab car after traveling about half its length, destroying about one-quarter of the passenger seats in the car.
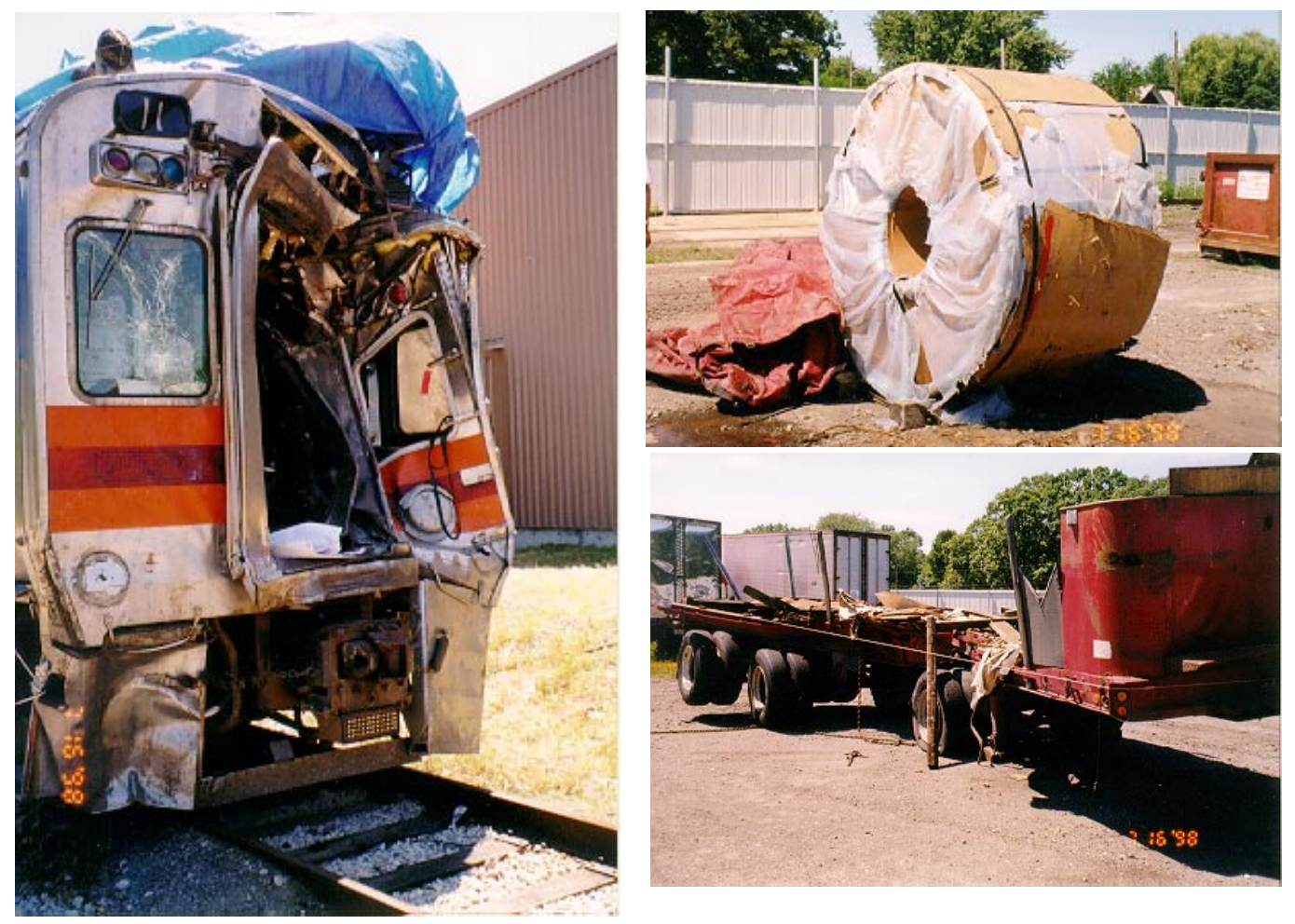

Figure 20. Post-collision photographs, cab car, truck trailer, and steel coil involved in Portage, Indiana grade crossing collision.

The end frame of the cab car is schematically shown in Figure 21. In cross-section, the collision posts have an I-beam shape. These posts were fabricated from sheet steel, and the widths of the two flanges are different. The collision post webs also included doublers, which extended from the base up to a point approximately $762 \mathrm{~mm}$ (30 inches) above the floor.

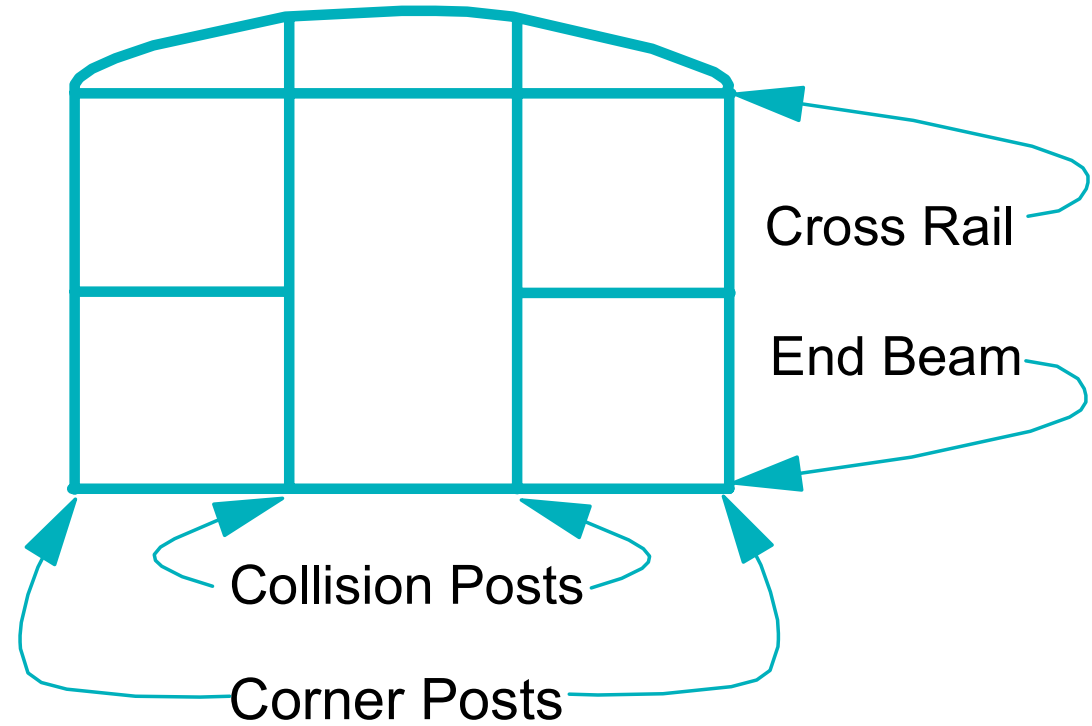

Figure 21. Schematic illustration of cab car end frame structure. 
The coil struck one of the cab cars collision posts and it fractured. The fracture occurred near the impact point, which corresponds to the location where the doublers on the flanges ended. The fracture of the collision post is shown in Figure 22.

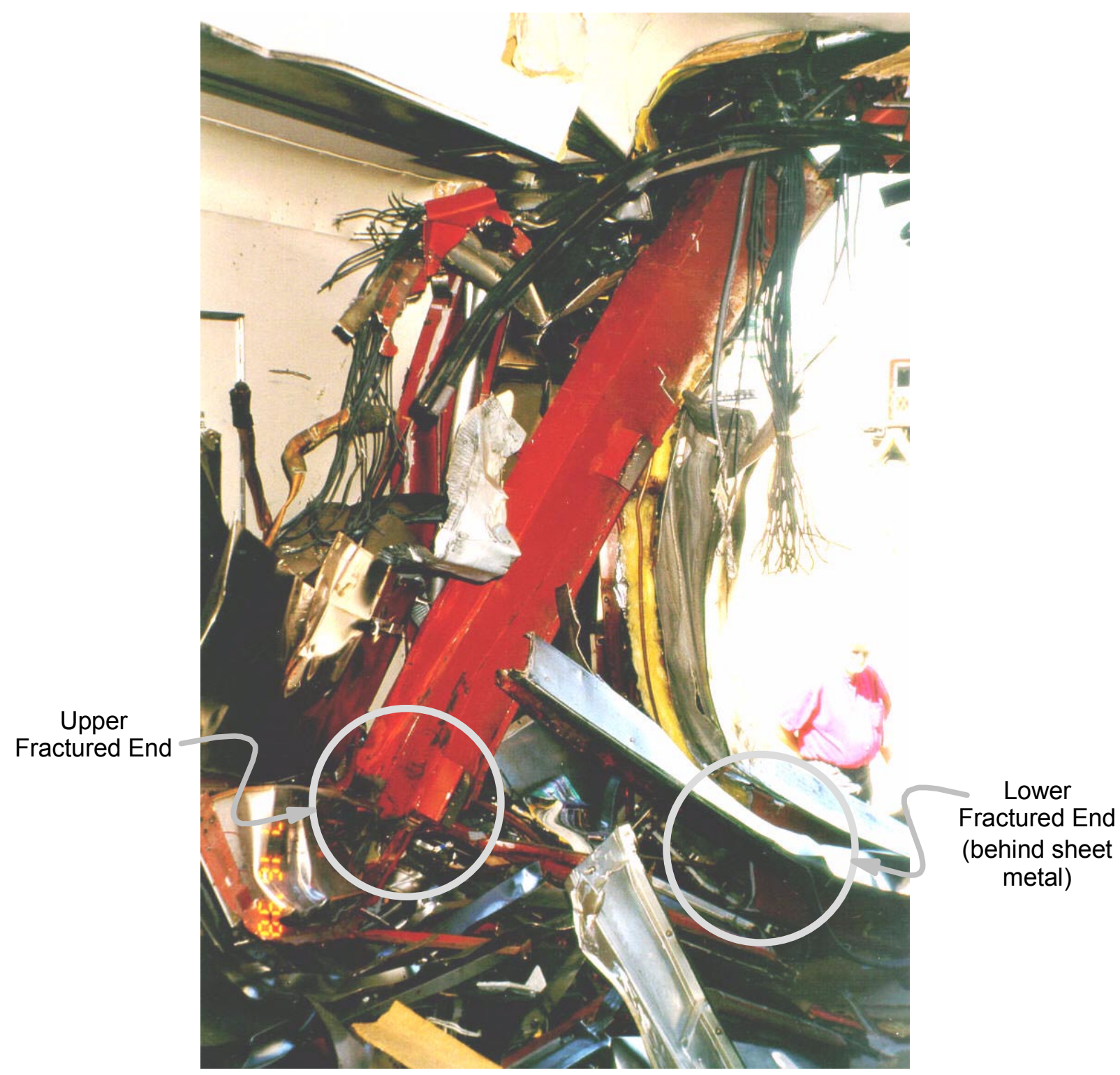

Figure 22. Post-collision photograph, cab car collision post fracture, Portage, Indiana grade crossing collision.

A simulation model has been developed based on this accident, to evaluate the influence of structural modifications on the consequences of the accident, and to evaluate the potential consequences of a similar accident where the coil strikes the corner post rather than the collision post (8). The results of analyses conducted with this model indicate that using the lateral end frame members to support the collision posts and corner post can significantly increase the crashworthiness of the cab car. Increased strength of the cross rail allows more effective distribution of the load and the crush among both collision posts and corner posts when one post is loaded. By integrating the end structure and by increasing the strength of the collision post by $25 \%$, the maximum safe collision speed for the operator can be increased from 19 to $31 \mathrm{kph}(12$ to $19 \mathrm{mph}$ ) in a collision similar to the Portage, Indiana grade crossing 
collision. With the same modifications, the maximum safe speed for the passengers can be increased from 32 to $48 \mathrm{kph}$ (20 to $30 \mathrm{mph}$ ).

\subsubsection{Selma, North Carolina, May 16, 1994}

An overhanging intermodal trailer on the northbound freight train was obstructing the right of way of the southbound intercity passenger train. The northbound freight train was traveling approximately $56 \mathrm{~km} / \mathrm{h}(35 \mathrm{mph})$ and the southbound passenger train was travelling about 120 $\mathrm{km} / \mathrm{h}(75 \mathrm{mph})$. The forward trailer on the $51^{\text {st }}$ car was overhanging the southbound track and engaged the lead locomotive of the passenger train. At the onset of contact, the trailer was above the deck and offset outside of the collision posts of the passenger train lead locomotive. The assistant engineer was killed during the accident and the engineer was severely injured. Figure 23 schematically depicts the conditions that initiated the oblique impact.

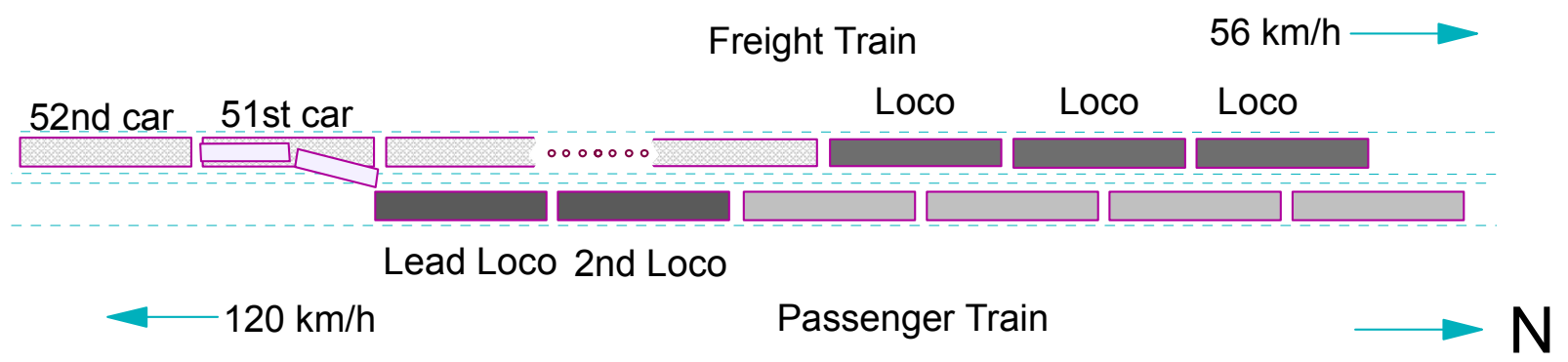

\section{Figure 23. Schematic drawing, initial conditions of Selma, North Carolina oblique collision.}

Damage to the short hood began at the right front corner and extended along the right side to the control compartment. The lead locomotive in the passenger train derailed and rolled over, coming to rest on its left side. All but one of the trailing cars, as well as the second locomotive, left the track, but remained upright. Only the last two cars in the freight train derailed and were damaged. The trailer, which was full of cat litter, burst open, spilling its contents along the track. The flatcar carrying the intruding trailer came to rest about $12 \mathrm{~m} \mathrm{(40}$ $\mathrm{ft}$ ) off the track in an upright position with the deck and end bent. Figure 24 schematically depicts the conditions immediately after the accident.

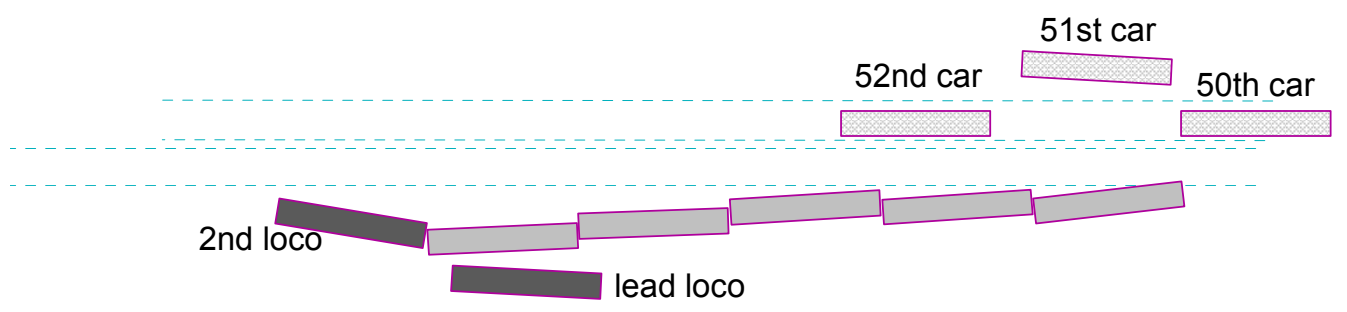

Figure 24. Schematic drawing, final conditions of Selma North Carolina oblique collision.

Figure 25 illustrates the damage to the locomotive from the impact with the container. The container initially impacted the sheet metal of the short hood approximately $229 \mathrm{~mm}$ (9 in) from the side of the locomotive. The damage extended back approximately $2.3 \mathrm{~m}(7.5 \mathrm{ft})$. For approximately the first $1.5 \mathrm{~m}(5 \mathrm{ft})$, the principal damage was to the short hood. For the remaining $0.8 \mathrm{~m}(2.5 \mathrm{ft})$ the principal damage included deformation of the sub-base and the sheet metal on the side of the operator's cab. The sub-base was the structure that provides the floor for the operator's cab and, beneath the floor, space for batteries and other ancillary 
equipment. The locomotive in the accident was a General Motors/ElectroMotive Division F$40 \mathrm{PH}$.

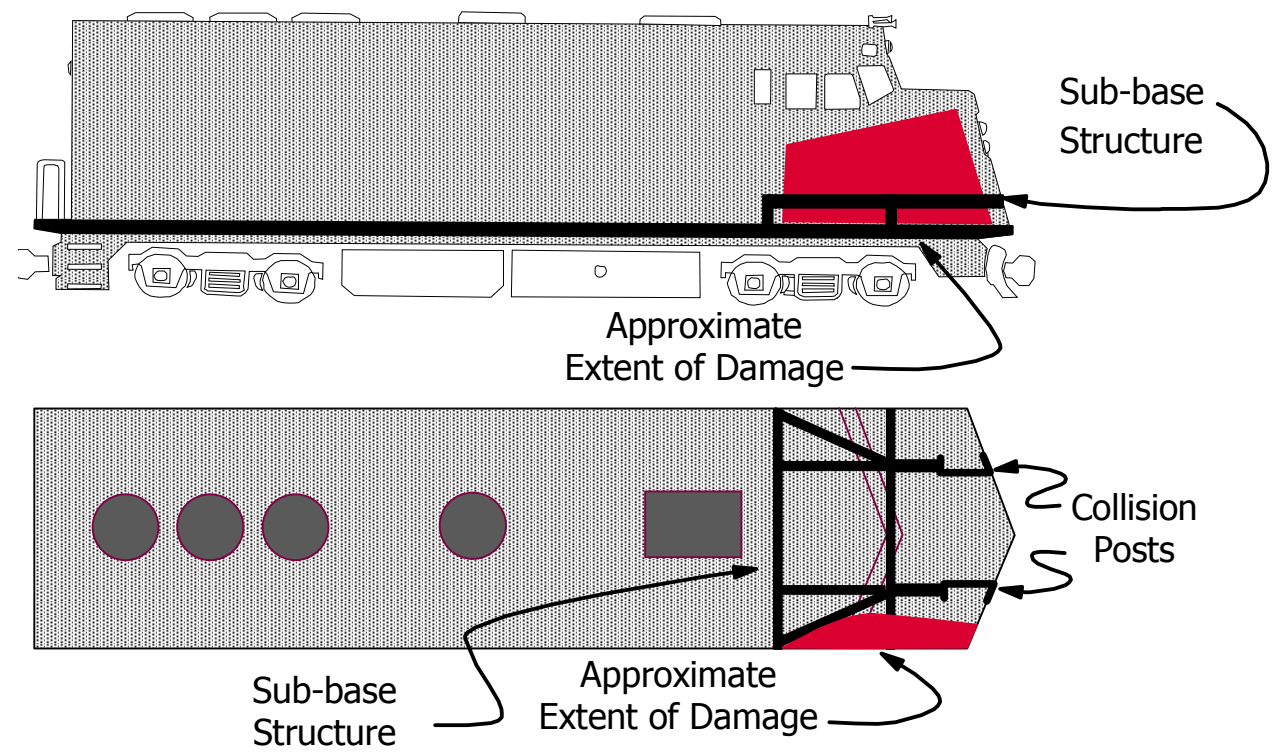

Figure 25. Schematic drawing, locomotive damage from impact with intermodal trailer, Selma, North Carolina oblique collision.

Potential modifications to improve the crashworthiness of locomotive designs have been evaluated with locomotive crush and train collision dynamics models, which simulate this oblique collision $(26,34,35)$. The maximum safe closing speed for the locomotive operator can be increased from 56 to $153 \mathrm{kph}$ (35 to $95 \mathrm{mph}$ ) by increasing the maximum strength crush strength of the short hood when it is loaded on the outboard corner from 445 to $1779 \mathrm{kN}$ (100 to 400 kips).

\subsection{Single Train Events}

Single train events such as derailments can result in the cars rolling on their sides or roofs. Such events are not generally associated with significant structural damage to the cars or loss of occupant volume due to structural crushing of the cars. Derailments can be associated with a large number of injuries, and, often depending on the post-derailment conditions, fatalities. Injuries such as those that have occurred during derailments can be mitigated with occupant protection measures. Efforts are underway to better understand the environment experienced by the occupants during a derailment, and to develop strategies for better protecting the occupants. Because there has been little structural damage in single train events, and detailed information on where occupants were and the mechanics of how they were injured has not yet been developed, the accident descriptions in this section are briefer than in preceding sections.

On September 22, 1993, around 2:53 am, a catastrophic accident occurred outside Mobile, Alabama on Big Bayou Canot Bridge (36). Shortly before the train passed over the bridge, a river barge and tug boat struck the bridge, and moved the tracks out of alignment. As a result, many of the cars of the long-haul inter-city train ended up in the river. 42 passengers and 5 crewmembers were killed, principally by drowning. There were also 103 injuries. The train was carrying 220 passengers and crew. Little can be done with traditional occupant protection measures to mitigate the consequences of such an accident. 
Single train events for which occupant protection measures may potentially help to mitigate the consequences include the derailment that occurred in Batavia, New York, on August 3, 1994 (37) and in Kingman Arizona on August 9, 1997 (24).

In the Batavia accident, the train derailed owing to a flattened rail head. The long-haul intercity train was traveling at $127 \mathrm{kph}(79 \mathrm{mph})$ when it derailed at 3:44 am. As a result of the derailment, most of the cars rolled onto their sides and down an embankment. There were 25 serious injuries, with a total of $10 \mathrm{crew}$ and 108 passengers were injured. The train was carrying 19 crewmembers and 320 passengers.

In the Kingman accident, the train derailed owing to washed out bridge supports. The longhaul inter-city train was traveling at $143 \mathrm{kph}(89 \mathrm{mph})$ when it derailed at 5:56 am. The train remained mostly intact, and all the cars remained upright. Four locomotives were hauling the train, and the lead three locomotives did uncouple from the rest of the train. After the bridge, the train tore up the much of the rails and ties. Many of the cars buckled in the sawtooth pattern. Of 294 passengers, there were 173 injured, 24 of them seriously. Of 18 crewmembers, there were 10 injured, 1 seriously.

In addition to gathering more information on how occupants are injured during derailments, efforts have also been initiated to determine the decelerations experienced by the occupants and to analyze the response of occupants in the interior during these decelerations. Derailments such as the one in Batavia can generate a large lateral deceleration when the car rolls onto its side and impacts the ground. The interior may present a potentially hostile environment under such circumstances.

\section{DISCUSSION}

Fatalities and injuries occur in passenger train collisions and derailments. In the eleven-year period from 1985 to 1995, 130 people were killed and 6,239 people were injured in inter-city and commuter passenger train accidents in the United States (38). There are 0.4 fatalities per passenger kilometer, in comparison with 6 fatalities per passenger kilometer for automobiles and 0.15 fatalities per passenger kilometer for aircraft (4).

The accidents themselves guide efforts to determine how the accidents unfolded, and to determine what features may provide improved occupant protection. Statistics do not necessarily provide a good basis for predicting the future. Both the types of accidents and the frequency may vary significantly from the past. Changes in the system, such as increased traffic, increased equipment speed, and increased size can significantly alter the potential for accidents. Amtrak has recently introduced the high-speed Acela trainset for service from Boston to New York to Washington, with speeds up to $240 \mathrm{kph}$ (150 mph). The Maryland Area Rail Commuter Service has recently introduced commuter service at speeds up to 200 kph (125 mph). Commuter rail service has recently been started in Seattle, Washington. Increasing traffic densities, increased equipment speed, and increasing size of the passenger rail system continue to generate a high level of concern about collision safety.

Ongoing research into rail equipment crashworthiness extends from field investigations of the causes of occupant injury and fatality in train accidents, to full-scale testing of existing and modified designs under conditions intended to approximate accident conditions, to investigations of the fundamental mechanics of structural crush. 
The objective of the field investigations is to develop potential means of increased occupant protection in accidents by determining the types of injuries that occur in train accidents, the locations on the train where the occupants were injured, and the mechanisms that potentially caused the injuries. This study is part of the effort to reduce injuries in train accidents.

A series of tests have been planned to measure the crashworthiness performance of existing design equipment and to measure the performance of equipment incorporating crushable end structures (39). The collision scenario addressed by these tests is a locomotive-led passenger train colliding with a cab car led passenger train on tangent track. Information from the accidents that occurred in Bourbonnais, Illinois, and Silver Spring, Maryland, which are both described in this paper, as well as other accidents, was used to develop this idealized test scenario. The tests planned for each equipment type are as follows:

1. Single-car impact into a fixed barrier

2. Two coupled car impact into a fixed barrier

3. Cab car-led train collision with standing locomotive-led train

The overall objectives of these tests are to demonstrate the effectiveness of

- improved-crashworthiness cab car structural designs

- improved-crashworthiness coach car structural designs

- improved-crashworthiness passenger and operator interior configurations

To date, the first two tests for existing-design equipment have been conducted. The third test, to complete the characterization of the performance of existing design equipment in an in-line collision, is tentatively planned for July 2001. Testing of improved crashworthiness design equipment, incorporating crushable end structures, is planned to start in the fall of 2002.

A similar series of tests to evaluate the effectives of existing equipment and modified equipment under conditions intended to approximate a grade crossing collision is being planned. The test scenario will be based on information from the accident in Portage, Indiana, which is described in this paper, along with information from other accidents.

The information from the full-scale tests is being used for comparison with analytic models and to determine what model features and refinements are necessary to accurately simulate the tests. Finite-element analysis techniques for evaluating structural crush are also being compared with closed-form analysis results of simplified and idealized rail equipment structures (34). Kinematic models, which allow closed form analysis, can provide a high level of assurance that fundamental mechanics and material behavior are incorporated correctly into detailed computational models. Subscale tests of these idealized and simplified rail car structures are also being performed, for comparison with kinematic and finite-element models.

The structural crashworthiness and occupant protection features of the train can act to reduce injuries and fatalities. Computers and computer-aided engineering tools have allowed the economical evaluation of the effectiveness of proposed structural crashworthiness and occupant protection features. Destructive testing for such proposed features, as is commonly done in the automotive industry, is expensive for rail equipment, which can cost up to $\$ 2$ million per car. These engineering tools have reduced the need for testing, and have also increased the utility of less expensive tests, such as component and substructure tests. 
These engineering tools have permitted the development of crashworthiness standards that prescribe equipment performance under conditions closely related to the conditions expected in a collision (3). Such standards require few assumptions on the design approach or on the design details of the equipment. Demonstration of compliance with performance standards generally requires destructive testing or detailed simulation with computer-aided engineering tools. Modern engineering tools have minimized the need for expensive tests.

\section{ACKNOWLEDGEMENTS}

This work described in this paper was performed as part of the Equipment Safety Research Program sponsored by the Office of Research and Development of the Federal Railroad Administration. The author would like to thank Dr. Tom Tsai, Program Manager, and Ms. Claire Orth, Division Chief, Equipment and Operating Practices Research Division, Office of Research and Development, Federal Railroad Administration, for their support. The author would also like to thank Mr. Grady Cothen, Deputy Associate Administrator for Safety Standards and Program Development for his support and assistance in investigating accidents. Finally, the author would like to thank Ms. Kristine Severson, Senior Engineer, Volpe Center, Mr. Eloy Martinez, Senior Engineer, Volpe Center, and Professor A. Benjamin Perlman, Tufts University, for reviewing this paper.

\section{REFERENCES}

1. Federal Railroad Administration, Office of Research and Development, "Improving Railroad Safety and Rail Passenger Technology through Targeted Research and Demonstrations, 1992-1997”, DOT/FRA/ORD-99/02, August 1999.

2. U.S. Department of Transportation, Federal Railroad Administration, "49 CFR Part 216 et al, Passenger Equipment Safety Standards; Final Rule”, May 12, 1999.

3. Tyrell, D., "U.S. Rail Equipment Crashworthiness Standards", Institute of Mechanical Engineers, May 2001.

4. Bing, A., "Collision Avoidance and Accident Survivability, Volume 1: Collision Threat" DOT/FRA/ORD-93-02.I, FRA, U.S. Department of Transportation, March 1993.

5. Bing, A., "An Approach to Evaluating Railroad Risks," A. Bing, page I-1-25. Rail Vehicle Crashworthiness Symposium, DOT/FRA/ORD-97/08, March 1998.

6. Mayville, R.A., Stringfellow, R.G., Rancatore, R.J., Hosmer, T.P., "Locomotive Crashworthiness Research, Volumes 5: Cab Car Crashworthiness Report" DOT/FRA /ORD-95 /08.5, 1996.

7. Mayville, R.A., Rancatore, R.J., Tegler, L., "Investigation and Simulation of Lateral Buckling in Trains," Proceedings of the 1999 IEEE/ASME Joint Railroad Conference, April 13-15, 1999, IEEE Catalog Number 99CH36340, ASME RTD Volume 16, 1999.

8. Stringfellow, R.G., Mayville, R.A., Rancatore, "A Numerical Evaluation of Protection Strategies for Railroad Cab Car Crashworthiness," Proceedings of the 8th ASME Symposium on Crashworthiness, Occupant Protection and Biomechanics in Transportation November 14-19, 1999; Nashville, Tennessee, 1999. 
9. Tyrell, D., Severson, K., Perlman, A.B., March, 2000, "Single Passenger Rail Car Impact Test Volume I: Overview and Selected Results," U.S. Department of Transportation, DOT/FRA/ORD-00/02.1, March 2000.

10. Severson, K., "Development of Collision Dynamics Models to Estimate the Results of Full-scale Rail Vehicle Impact Tests" Tufts University Master's Thesis, November 2000.

11. Severson, K., Tyrell, D., Perlman, A.B., "Rail Passenger Equipment Collision Tests: Analysis of Structural Measurements," presented at the 2000 International Mechanical Engineering Congress and Exposition, November 6, 2000, Orlando, Florida.

12. Tyrell, D.C., Severson, K.J., Marquis, B.J., "Train Crashworthiness Design for Occupant Survivability," ASME International Mechanical Engineering Congress and Exposition, AMD-Vol. 210, BED-Vol. 30, pp. 59-74, 1995.

13. Tyrell, D.C., Severson, K.J., Marquis, B.J., "Evaluation of Selected Crashworthiness Strategies for Passenger Trains," Transportation Research Record 1489, Rail, pp. 50-58, 1995.

14. Mayville, R.A., Stringfellow, R.G., Rancatore, "Development of a Passenger Rail Vehicle Crush Zone," Proceedings of the 1999 IEEE/ASME Joint Railroad Conference, April 1315, 1999, IEEE Catalog Number 99CH36340, ASME RTD Volume 16, 1999.

15. Tyrell, D.C., Severson, K.J., Marquis, B.J., 1995, "Analysis of Occupant Protection Strategies in Train Collisions," ASME International Mechanical Engineering Congress and Exposition, AMD-Vol. 210, BED-Vol. 30, pp. 539-557.

16. Tyrell, D., Severson, K.J., "Crashworthiness Testing of Amtrak’s Traditional Coach Seat”, U.S. Department of Transportation, DOT/FRA/ORD-96/08, October 1996.

17. VanIngen-Dunn, C., March 2000, "Single Passenger Rail Car Impact Test Volume II: Summary of Occupant Protection Program," U.S. Department of Transportation, DOT/FRA/ORD-00/02.2.

18. Tyrell, D., Zolock, J., VanIngen-Dunn, C., "Rail Passenger Equipment Collision Tests: Analysis of Occupant Protection Measurements," presented at the 2000 International Mechanical Engineering Congress and Exposition, November 6, 2000, Orlando, Florida.

19. National Transportation Safety Board, "Collision and Derailment of Maryland Rail Commuter MARC Train 286 and National Railroad Passenger Corporation AMTRAK Train 29 Near Silver Spring, MD February 16, 1996”, RAR-97-02, 06/17/1997.

20. Tyrell, D.C., Severson, K.J., Mayville, R.A., Stringfellow, R.G., Berry, S., Perlman, A.B., 1997, "Evaluation of Cab Car Crashworthiness Design Modifications," Proceedings of the 1997 IEEE/ ASME Joint Railroad Conference, IEEE Catalog Number 97CH36047.

21. National Transportation Safety Board, "Amtrak Train 87 Derailment after Colliding with Intermodal Trailer from CSXT Train 176 Selma, North Carolina May 16, 1994", RAR-9502 , adopted on $03 / 21 / 1995$.

22. National Transportation Safety Board, "Rear-End Collision of Amtrak Passenger Train 94, The Colonial and Consolidated Rail Corporation Freight Train ENS-121, on the Northeast Corridor, Chase, Maryland January 4, 1987’, RAR-88-01, January 1988. 
23. National Transportation Safety Board, "Head On Collision of National Railroad Passenger Corporation (Amtrak) Passenger Trains Nos. 151 and 168, Astoria, Queens, New York, NY, July 23, 1984”, RAR-85-09, May 1985.

24. National Transportation Safety Board, "Derailment of Amtrak Train 4, Southwest Chief, on the Burlington Northern Santa Fe Railway near Kingman, Arizona August 9, 1997”, RAR-98-03, 1998.

25. Mayville, R.A., Stringfellow, R.G., Rancatore, R.J., Hosmer, T.P., 1995, "Locomotive Crashworthiness Research, Volume 2: Design Concept Generation and Evaluation" DOT/FRA/ORD-95/08.2.

26. Tyrell, D., Severson, K., Marquis, B., Martinez, E., Mayville, R., Rancatore, R., Stringfellow, R., Hammand, R., Perlman, A.B., 1999, "Locomotive Crashworthiness Design Modifications Study," Proceedings of the 1999 IEEE/ASME Joint Railroad Conference, April 13-15, 1999, IEEE Catalog Number 99CH36340, ASME RTD Volume 16.

27. Tyrell, D.C., Severson, K.J., Marquis, B.J., 1995, "Train Crashworthiness Design for Occupant Survivability," ASME International Mechanical Engineering Congress and Exposition, AMD-Vol. 210, BED-Vol. 30, pp. 59-74.

28. Scholes, A., and Lewis, J., 1993, "Development of Crashworthiness for Railway Vehicle Structures", Proceedings of the Institute of Mechanical Engineers, Vol. 207 Part F: Journal of Rail and Rapid Transit.

29. Lacôte, F., Cléon, L.-M., Lagneau, H., Dannawi, M., Demonsant, E., Wiart, A., 1993, “Les Tolérances à la Collision Des Matérials Ferroviaires," Revue générale des chemin de fer, Gauthier-Villars.

30. Ohnishi, T., Kawakami, N., Sano, A., 1993, "Crashworthiness of Train,” The International Conference on Speedup Technology for Railway and Maglev Vehicles, Vol. I, PS2-15, the Japanese Society of Mechanical Engineers (JSME).

31. National Transportation Safety Board, "Railroad Accident Report Near Head-on Collision and Derailment of Two New Jersey Transit Commuter Trains Near Secaucus, New Jersey February 9, 1996", RAR-97-01, 03/25/1997.

32. Mayville, R.A., Hammond, R.P., Johnson, K.N., 1999, "Static and Dynamic Crush Testing and Analysis of a Rail Vehicle Corner Structural Element," Proceedings of the 8th ASME Symposium on Crashworthiness, Occupant Protection and Biomechanics in Transportation November 14-19, 1999; Nashville, Tennessee.

33. National Transportation Safety Board, "Collision of Northern Indiana Commuter Transportation District Train 102 with a Tractor-Trailer Portage, Indiana June 18,1998”, RAR-99-03, 07/26/1999.

34. Tyrell, D.C., Martinez, E.E., Wierzbicki, T., "Crashworthiness Studies of Locomotive Wide Nose Short Hood Designs," Crashworthiness, Occupant Protection and Biomechanics in Transportation Systems, American Society of Mechanical Engineers, AMD Vol. 237/BED Vol. 45, 1999. 
35. Tyrell, D., Severson, K., Marquis, B., Perlman, A.B., "Simulation of an Oblique Collision of a Locomotive and an Intermodal Container," Crashworthiness, Occupant Protection and Biomechanics in Transportation Systems, American Society of Mechanical Engineers, AMD Vol. 237/BED Vol. 45, 1999.

36. National Transportation Safety Board, "Derailment of Amtrak Train No. 2 on the CSXT Big Bayou Canot Bridge Near Mobile, Alabama September 22, 1993”, RAR-94-01, 09/19/1994.

37. National Transportation Safety Board, "Derailment of Amtrak Train 49 On Conrail Trackage Near Batavia, New York on August 3, 1994”, RAR-96-02, 07/11/1996.

38. Peacock, T., "The Need for Rail Passenger Equipment Structural Standards", page I-2-15, Rail Vehicle Crashworthiness Symposium, March 1998, DOT/FRA/ORD-97/08.

39. Tyrell, D., Severson, K., Perlman, A.B., Brickle, B., VanIngen-Dunn, C., "Rail Passenger Equipment Crashworthiness Testing Requirements and Implementation," presented at the 2000 International Mechanical Engineering Congress and Exposition, November 6, 2000, Orlando, Florida. 